\title{
Auf dem Weg zur Philosophie
}

1869 hatte Nietzsche die Idee, ein Buch mit vermischten Inhalten zu schreiben. Da er sich über die Schicklichkeit dieses Unternehmens unsicher war, fragte er seinen Mentor Friedrich Ritschl um Rat:

\begin{abstract}
Wenn Sie sich sodann nach meiner nächsten größeren Publikation erkundigen, so wäre mir gerade in diesem Puncte ein wohlwollend-eindringlicher Rath von grösstem Werthe. Um nämlich ein größeres Buch mit fortlaufender Entwicklung eines Grundgedankens fertig zu machen, fehlt es mir augenblicklich an Allem, bei der Art meiner jetzigen Collegienvorbereitung, die mich zwingt, zum Alltagsbedarf das Quantum Productivität aufzuzehren. Doch... es kann ja nicht immer so bleiben - Dagegen könnte ich, nicht ohne Wollust, einen hübschen Band vermischtester Dinge, ein rechtes «Leipziger Allerlei» zusammenstellen, theils litterarhistorische Erkenntnisse, theils neue Ansichten und Aussichten, drittens ein tüchtiges Bündel von Coniecturen zu Aeschylus Sophocles Lyrikern Laertius usw. Warum sollte es nicht erlaubt sein, mit einer solchen lustigen Buntheit und Unordnung ans Tageslicht zu kommen, nöthigenfalls unter halber Anonymität? Vielleicht wird so ein Miscellenbuch gar nicht ungern gelesen. Sagen Sie mir doch ein entschiedenes und entscheidendes Ja! oder Nein! ${ }^{1}$
\end{abstract}

Damals war ein «Miscellenbuch» für Nietzsche noch klar unterschieden von einem «Buch mit fortlaufender Entwicklung eines Grundgedankens». Nietzsche unterscheidet die beiden Buchtypen durch Produktionsdauer und -kraft, welche beim einen niedrig, beim anderen hoch sind. Das «Miscellenbuch» legitimiert er einerseits durch seine «Wollust», andererseits durch die allfällige Lust der Leser. Es handelt sich um ein Buch mit neuen und werdenden «Ansichten und Aussichten», das zwischen den «grösseren Büchern» steht. Ritschl antwortete auf Nietzsches Frage mit einem «entschiedene[n] Nein» und erklärte das wie folgt: «Später haben Sie Freiheit, in diesem lockern, kaleidoskopischen Genre zu machen, was und soviel Sie wollen. Aber das Recht dazu müssen Sie sich meo voto erst erkaufen durch etwas Zusammenhängendes, Einheitliches.» ${ }^{2}$ Damit hielt Ritschl seinem jungen Kollegen die akademische Werkpolitik entgegen, gemäss der es ein Vorrecht der Reife, des Verdienstes und der Weisheit ist, in lockerem Stile zu publizieren.

1 N. an Ritschl, 9.10.1869, Nr. 35, KGB II 1, S. 65 f.

2 Ritschl an N., 5.11.1869, Nr. 38, KGB II 2, S. 75.

(C) WILHELM FINK VERLAG, 2019 | DOI:10.30965/9783846764053_005

This is an open access chapter distributed under the terms of the prevailing CC-BY-NC-ND License at the time of publication. 
Zehn Jahre nach diesem Briefwechsel hat Nietzsche drei «kaleidoskopische» Aphorismenbücher publiziert. Seine Professur hat er niedergelegt und sein Basler Domizil aufgelöst. Vom Kurgastleben zum Schreibverfahren bis zur Werkpolitik hat sich Nietzsche auf die Produktion von «Miscellenbüchern» eingestellt. Auf dem Weg zu seiner Philosophie bildet der Wanderer deshalb einen Meilenstein. Nietzsche verfügt 1879 über ein Schreibverfahren, das ebenso die Sammlung eines bunten Allerleis wie die Verdichtung dieses Materials zur Buchform zulässt. Im ersten Teil wird darum das Verhältnis von Nietzsches Autorschaft zum Material, zum Schreibverfahren und zum Aphorismenbuch behandelt (4.1). Die Fokussierung auf aktuelle Notate und deren rasche Verwertung sind eingebettet in die Philosophie des Werdens, welche den je momentanen Denkzustand des Philosophen verarbeitet. Die Entscheidung, das eigene Werden in die Philosophie einzubeziehen, bedarf spezifischer Schreibund Publikationsstrategien. Denn das persönliche Werden muss aufgezeichnet und weiterem Wandel zugänglich gemacht werden. Es wird gezeigt, dass Nietzsches Philosophie mit der Schreib- und Publizierweise der ersten drei Aphorismenbücher integral zusammenhängt (4.2). Die Philosophie des Werdens ist daher Philosophie, Schreibverfahren und Werkpolitik in Einem. Abschliessend will ich ausgehend von diesen Erkenntnissen auf die Grundfrage zurückkommen, was die Werkstatt der Philosophie sei (4.3).

\subsection{Philosophische Autorschaft und Material}

In dieser Dissertation wurde exemplarisch anhand von Nietzsches Wanderer das Verhältnis von philosophischer Autorschaft, Schreibsituation und Material untersucht. Wie gezeigt ist der Rahmendialog zwischen Wanderer und Schatten selbstreflexiv auf Autorschaft, Schreiben und Lesen bezogen. Dass die Schreibsituation dem spazierenden Autor Nietzsche in keiner Weise untergeordnet ist, zeigte sich exemplarisch im Arbeitstitel «St. Moritzer Gedanken-Gänge». Es werden im Folgenden die Bedeutung des Materialbegriffs, der Dynamik von Schreibfluss und Buchform sowie des Aphorismenbuchs für Nietzsches Autorschaft dargelegt.

\subsubsection{Der Philosoph und sein Material}

Für Nietzsche gibt es vom Material her betrachtet keine substanziellen Unterschiede zwischen der Tätigkeit des Künstlers, des mechanischen Erfinders und des historischen Gelehrten (Kap. 3.1.1). Alle drei arbeiten mit und am Material: «Das Genie thut auch Nichts, als dass es erst Steine setzen, dann bauen lernt, 
dass es immer nach Stoff sucht und immer an ihm herumformt.» ${ }^{3}$ Im Arbeitsprozess werden vorhandene Stoffe als Material genutzt (seien es physische Materialien, Beobachtungen oder Gedanken). In diesem Sinne versteht Nietzsche auch seine Lektüre als Material:

Die Frage «welche Bücher hat ein Autor benutzt?» hat wenig Aussicht auf präzise Beantwortung, wenn jener Autor ein sein[en] Quellenschriftstelle[r]n überlegen[er] Kopf ist, der mit voller Freiheit über sie schaltet u. waltet und der alles, was er an Material aus ihn[en] entnimmt, in neue Form gießt und mit dem Stempel seiner Individualität versieht. ${ }^{4}$

Durch den Fokus auf das Material verliert die intentio auctoris auch bei der Lektüre an Bedeutung. Man liest als Philosoph Bücher, um darin Material für eigene Gedanken und Bücher zu finden. Das Lesen von Büchern dient als Material für das Schreiben. Der Philosoph liest, notiert, exzerpiert - und schreibt. Dies wird exemplarisch sichtbar an Nietzsches Bemerkung über die stets steigende Menge anthropologischer Studien, welche er als «Sammlung eines ungeheuren empirischen Materials der Menschenkenntniss» bezeichnet und für sein Buch Menschliches verarbeitet. ${ }^{5}$ Mit demselben materialen Werkbegriff beschreibt Nietzsche Schuberts Werke als «einen Schatz von unverbrauchten Erfindungen»: Musiker würden «noch ein paar Jahrhunderte an seinen Gedanken und Einfällen zu zehren haben». ${ }^{6}$ Und so wundert es nicht, dass Nietzsche in der Genealogie der Moral die Quellen seiner Moralstudien als «Material» bezeichnet:

Um wenigstens eine Vorstellung davon zu geben, wie unsicher, wie nachträglich, wie accidentiell «der Sinn» der Strafe ist und wie ein und dieselbe Prozedur auf grundverschiedne Absichten hin benützt, gedeutet, zurechtgemacht werden kann: so stehe hier das Schema, das sich mir selbst auf Grund eines verhältnissmässig kleinen und zufälligen Materials ergeben hat. ${ }^{7}$

Das Material ergibt jemandem etwas («sich mir selbst [...] ergeben hat»). Die darauffolgende Aufzählung verschiedener Modi von Strafen ist mitunter eine Zusammenfassung von Nietzsches Exzerpten aus Albert Hermann

3 MA 162, KSA 2, S. 152.

4 NL 1868, 69[4], KGW I 5, S. $38 f$.

5 NL 1875, 8[4], KSA 8, S. 129; vgl. Orsucci 1996, S. 8-52.

6 WS ${ }_{155}$, KSA 2, S. 617 .

7 GM II 13, KSA 5, S. 317. 
Posts Bausteine für eine allgemeine Rechtswissenschaft auf vergleichendethnologischer Basis $(1880 / 81) .{ }^{8}$

Christian Benne und Enrico Müller stellen fest: «Nietzsche denkt das «Material> eben nicht mehr im Sinne der Tradition als schon existierende Materie, die wie der Ausgangsstoff des Bildhauers nur noch zur Plastik geformt wird. Vielmehr wird das Material im Prozess der Formgebung miterzeugt.» ${ }^{9}$ Das zeitgenössische Sinnbild dieses materialen Autorschaftsmodells sind, wie in Kap. 3.1 gezeigt, die Notizbücher Beethovens, welche die 〈genialen〉 Kompositionen als Produkte intensiver, kontinuierlicher und langwieriger Arbeit kenntlich machen. Auch in Nietzsches Notizbüchern materialisiert sich der Arbeitsprozess des Schreibens. Nietzsches Schreibverfahren ist die praktische Reaktion auf Kleists Einsicht, dass Gedanken allmählich verfertigt sind. ${ }^{10}$ Lag Kleists Fokus aber noch auf der Verfertigung von Gedanken im Gespräch mit anderen, sucht Nietzsche das Gespräch mit den materialen Bedingungen des Schreibens und Lesens.

Auf Seiten der Leser folgt aus dem materialen Philosophieverständnis eine aktive Lektüre und damit vielfache Möglichkeiten der Anregung und Weiterverarbeitung (Kap. 3.2.3). Nietzsche produzierte in den späten 1870er Jahren Bücher, welche dem Leser mehr Materialsammlungen als fertige Bauwerke präsentieren:

Irrthum der Philosophen - Der Philosoph glaubt, der Wert seiner Philosophie liege im Ganzen, im Bau: die Nachwelt findet ihn im Stein, mit dem er baute und mit dem, von da an, noch oft und besser gebaut wird: also darin, dass jener Bau zerstört werden kann und d o ch n o ch als Material Werth hat..1

Aphorismenbücher sind Material für die Leser, womit auch hier nicht länger die intentio auctoris bzw. der «Bau» massgebend ist. Der Text hat einen offenen Deutungshorizont, für den der empirische wie auch implizite Autor nicht mehr verantwortlich zeichnet: «Wer Etwas von mir verstanden zu haben glaubte, hat sich Etwas aus mir zurecht gemacht, nach seinem Bilde [...].»12 Diese materiale Autorschaft ist die Gegenposition zur Genieästhetik, welche sich für das Ganze, den Bau rühmt. Der Hinweis auf das Material zerstörter Bauten reflektiert den Buchtyp des Aphorismenbuchs, findet er sich doch in den lose geordneten Vermischten Meinungen. In diesem Kontext ist die Kritik

\footnotetext{
8 Vgl. Stingelin 1991. Die Exzerpte stehen im Nachlass von Frühjahr und Sommer 1883.

9 Benne/Müller 2014, S. 39.

10 Vgl. Kleist 2010.

11 VM 201, KSA 2, S. 466.

12 EH, KSA 6, S. 300.
} 
von Arthur C. Danto ein Missverständnis, wenn er Nietzsche einen «singular lack of architectonic talent» unterstellt. ${ }^{13}$

Je mehr die Aphorismensammlung als Material für die Leser daherkommt, desto wichtiger wird die Stellung des Autors zu seinem Buch: Das kam in den unverwendeten Reflexionen und Vorreden im Kap. 3.2.2 zur Sprache, in denen Nietzsche mit verschiedenen Leseanleitungen experimentierte. Je nach Inszenierung und Leseweise wirken die Aphorismen wie tiefgründige Sentenzen oder lose aneinandergereihte Anregungen. Ein materiales Buch, das verschiedene Leseweisen nahelegt, bedarf einer Form der auktorialen Stellungnahme oder Inszenierung. Aphorismenbücher erweisen sich daher nicht nur als Material für die Leser, sondern auch für die Autorschaftskonstruktion.

\subsubsection{Schreibfluss vs. Buchform}

Der philosophische Arbeitsprozess ist geprägt durch eine je individuelle Dynamik von Schreibfluss und Verknappung. Schreiben ist keine isolierte Tätigkeit, sondern mit dem Büchermachen verbunden. Dass Nietzsche so viele Bücher erfolgreich abgeschlossen hat, lässt darauf schliessen, dass er das Mass von Schreibfluss (Manuskripte) und Buchform (Publikationen) zu einer beidseits hohen Produktivität gebracht hat. Es ist aus Sicht des Schreibflusses charakteristisch, dass ihm ein umso stärkerer Buchgedanke entgegengesetzt werden muss.

Das Buchformat kann den Schreibfluss durch seine heterogenen Produktionsbedingungen zugleich hemmen und befördern: Das Umschreiben führt zu einem Drucktext oder ist Ausgangspunkt endloser Umarbeitung. Dafür gibt es zahlreiche Beispiele in der Philosophie- und Literaturgeschichte sowie in Nietzsches Schaffen. ${ }^{14}$ Deshalb sind die mit der Buchherstellung verbundenen «Fixpunkte» wie die Publikationsankündigung oder Druckfahnenkorrektur nötig, um den Schreibfluss zu regulieren. ${ }^{15}$

13 Danto 2005, S. 4.

14 Einige Publikationsgeschichten aus Nietzsches Gesamtwerk bezeugen den unaufhörlichen Bearbeitungsprozess seiner Schriften. So etwa die Publikationsgeschichte der Fröhlichen Wissenschaft insbesondere ihre Überarbeitung, vgl. Kaufmann 2015a. Auch der an Freunde versendete «vierte und letzte Theil» von Also sprach Zarathustra stand im Sommer 1885 bereits wieder im Fokus von Erweiterungen, vgl. Röllin 2012, S. 103-112. Für den Konflikt zwischen Schreiben und Buchform beim späten Nietzsche vgl. Thüring 2008, bes. S. 135 .

15 Vgl. Benne 2015a, S. 632: «Das autodiaskeuastisch-rhapsodische Schreiben auf der Grundlage des eigenen handschriftlichen «Materials», vom Autor nicht nur hervorgebracht, sondern immer wieder neu ediert, verlangte, wie zu sehen war, nach gelegentlichen Zäsuren, die typischerweise an die Herstellung und Publikation von Büchern gebunden sind. Erst durch die Schaffung derartiger Fixpunkte lässt sich der Schreibprozess aufrechterhalten.» 
Das charakteristische Problem von Nietzsches Arbeitsweise ist nicht das Produzieren von Text. Sein Schreibfluss ist durch die vermehrte Nutzung von Notizbüchern konstant. Damit aber aus den Heften ein publiziertes Werk entsteht, bedarf es Techniken der Verknappung. Die praktische Frage, welche sich bei Nietzsches Schreibverfahren stellt, ist jene, wie dabei ein buchförmiges Druckmanuskript entstehen soll: «wie konnten bei dieser Arbeitsweise Nietzsches Bücher entstehen?» ${ }^{16}$ Für die St. Moritzer Schreibsituation lassen sich folgende Schreibpraktiken ausmachen, die je verschiedene Funktionen bezüglich Schreibfluss und Buchform übernehmen (zur Übersicht siehe Tab. 1):

1. Notieren: Das Notieren ist weit über den Wanderer hinaus ein Charakteristikum für Nietzsches Arbeitsweise, besonders für die späten 1870er Jahre. Anders als beim frühen und späten Nietzsche dominieren in dieser Zeit der ersten Aphorismenbücher die Notizbücher. ${ }^{17}$ Die Klein-Oktavhefte dienen ihm nicht nur zur Aufzeichnung und Materialsammlung, sondern auch als Denktechnik. In der mobilen Schreibsituation von St. Moritz notiert Nietzsche ohne thematischen Fokus jederzeit und überall: «Nietzsche schreibt jetzt über alle Gegenstände, die in sein [sic] Bereich kommen, zu jeder Zeit seine Gedanken hin.» ${ }^{18}$ Notate verhindern laut Hans-Jörg Rheinberger durch ihre offene, prekäre und reversible Struktur, die «vorzeitige Schliessung» des epistemischen bzw. beim Wanderer des philosophischen Prozesses. ${ }^{19}$ Deshalb sind Selbstlektüre und Umschriften notwendig, welche stärker auf eine «Schliessung» zielen. Einmal mit Notieren begonnen, kann sich Nietzsche nur schwer dem Drang entziehen, ein Aphorismenbuch zusammenzustellen. ${ }^{20}$ Einerseits

Auch Spoerhase 2018 beschäftigt sich mit der Dynamik von Schreibphasen und Buchherstellung. Er zeigt, dass die Buchförmigkeit kein nachträgliches Resultat von Schreibprozessen ist, sondern diese auf verschiedene Weise formiert. Vgl. auch Campe 2010, der das Oszillieren zwischen Schreiben und Text anhand von Lichtenbergs Sudelbüchern aufzeigt.

16 Horneffer 1906, S. 67. Horneffer übersieht die Buchförmigkeit des Schreibverfahrens, wenn er behauptet, Nietzsche habe gar nie ein Buch geschrieben, sondern immer nur «Stücke» und wenige «Studien», die er nie zu einem einheitlichen Buch zusammenzufassen vermochte.

17 Vgl. Röllin 2012, S. 20: «von 1876 bis 1880, sind ganze 24 Notizhefte, aber nur 5 Arbeitshefte überliefert [...].»

18 Horneffer 1906, S. 74.

19 Rheinberger 2006, S. 353.

20 In diesem Kontext ist auch die folgende Briefstelle von Nietzsche an Gast interessant, nachdem Letzterer einen langen Brief mit vielen philosophischen Überlegungen gesandt hat: «zuletzt denke ich, Sie benutzen den Brief einmal, wenn Sie zur Erholung ein Bändchen Gedanken sammeln: für diesen Zeitpunkt hebe ich ihn auf.» (N. an Gast, 21.10.1879, Nr. 893, KGB II 5, S. 455) Man sammelt als erholsame Tätigkeit solange, bis ein «Bändchen Gedanken» zusammenkommt, als würde man Blumen pflücken bis man einen Blumenstrauss beisammen hat. 
drängen Notate zur Überarbeitung und Verwertung, andererseits verhindern sie die Verknappung des Materials. In St. Moritz ging Nietzsche umgehend ans Umschreiben und Verwerten der Notate. Sein Schreibfluss wird durch sein Schreibverfahren so konstant, dass es nun der Entscheidung bedarf, «nicht〉 zu schreiben. Deshalb nimmt sich Nietzsche nach Abschluss des Wanderers vor, den Winter über «nicht` zu denken, worauf ihm Marie Baumgartner feinfühlig antwortet: «Wenn Sie sagen, Sie wollen diesen Winter nicht denken, so freue ich mich insofern darüber weil ich annehme: Sie meinen damit blos, Sie wollten sich nicht vor nehmen zu denken, mit einer besonderen Absicht, etwa das Komponieren eines neuen Buches.» ${ }^{21}$ Indem Nietzsche sein alltägliches Denken als Ressource für Gedankensammlungen nutzt, gibt es kein Denken mehr, das nicht potenziell zu verarbeitbarem Notatmaterial wird. Die Entscheidung, nicht zu denken, heisst für den Nietzsche von 1879, keine Notizen zu machen, die potentiell wieder auf ein Buch hindrängen. Denken, Schreiben und Büchermachen sind kaum mehr voneinander trennbar. Es stimmt nämlich auch für den Wanderer, was Horneffer allgemein für Nietzsches Notierweise festgehalten hat: «Es ist, als ob er nicht für sich selbst schriebe, sondern von Anfang an die literarische Verwertung im Auge hätte [...].» ${ }^{22}$ Nietzsche ging es nicht um die Aufzeichnung aller persönlichen Gedanken, sondern um die in bestimmten Schreibsituationen entstehenden philosophischen Gedanken, d.h. für einen Schriftsteller, in literarische Form gebrachte Gedanken. Das Anfertigen vieler kurzer Entwürfe, das Schreiben täglicher Anekdoten in prägnanter Form oder das Umarbeiten wissenschaftlicher Erkenntnisse in den künstlerischen Aphorismenstil finden sich vielfach in seinen Notizbüchern. ${ }^{23}$ Zudem empfiehlt er Freunden dasselbe Vorgehen, um erfolgreich zu werden:

Thun Sie dies doch zuerst einmal the se nhaft, aphoristisch, in der knappsten Form und mit haarscharfem Ausdruck. Ein halbes Tausend musikalischer Einzelsätze und Beobachtungen von Ihnen, die Quintessenzen Ihrer

21 Baumgartner an N., 15.12.1879, Nr. 1264, KGB II 6/2, S. 1241; vgl. auch N. an Gast, 30.9.1879, Nr. 887, KGB II 5, S. 448: «Hier in Naumburg will ich keine Gedanken haben und jedenfalls keine a ufs chreiben : letzteres wenigstens ist Sache des Willens.»

22 Horneffer 1906, S. 61f.

23 Diese Gedanken ähneln daher dem antikontextuellen Exzerpieren, das der eigenen Anregung und Entwicklung dient. Vgl. Daston 2004, S. 445: «For example, the Renaissance humanist practice of excerpting short, pithy quotations from long texts for florilegia and commonplace books bears a close resemblance to the excerpting of short, pithy facts from the continuum of experience. Both practices were radically anti-contextual and antisystematic, ripping out morsels of eloquence and information for use elsewhere and quite possibly to very different ends.» Für die Nähe von ausformulierten Notaten und Aphorismen in der schriftstellerischen Produktion, vgl. Efimova 2018 S. 149-183. 
Erfahrungen - das giebt Ihnen Namen und Stellung. Nur nichts Periodisches und Kleines (seien es «Briefe〉 oder Aufsätze für Zeitschriften), bevor Sie Sich nicht erst als $\mathrm{G}$ a $\mathrm{n}$ ze s gezeigt haben! ${ }^{24}$

Freilich probt Nietzsche nicht an Hunderten von Entwürfen. Und anstatt mehrere Jahrzehnte zu warten, publiziert er in den späten $1870 e r$ Jahren dicke Bücher.

2. Spazierend denken in der St. Moritzer Schreibsituation: Nietzsche hält seine Denkbewegungen durch Spaziergänge am Laufen. Sein mobiles Schreibverfahren hat deshalb eine vom Körper ausgehende schreibökonomische Dimension: «das Unterwegssein [kann] zur Stimulanz des Schreibens werden, die das Aufzeichnen anreizt und antreibt.» ${ }^{25}$ Die Spaziergänge sind Produktionsstätten von Gedankenmaterial. Indem Nietzsche in St. Moritz spaziert, füllt er einige Notizbuchseiten. Für die Buchform kann das aber problematisch werden: Warum nicht ein paar Tage länger spazieren und auf weitere, vielleicht noch bessere Einfälle warten? Diesem Problem wirkt Nietzsche mit der Entscheidung entgegen, nur Gedanken der St. Moritzer Spaziergänge im Wanderer aufzunehmen. Der Entwurfstitel - «St. Moritzer Gedanken-Gänge» inszeniert das Buch als zeitliche Koinzidenz des St. Moritzer Aufenthalts. Damit war die Notiertätigkeit in einen überschaubaren zeitlichen und räumlichen Rahmen eingebettet. Nietzsche entscheidet sich 1879, an welchem Ort, zu welcher Zeit, mit welcher Ernährung und Luft, kurz in welcher Schreibsituation er seinen Schreibfluss gewähren lässt. Er begegnet der Gefahr eines unaufhörlichen Schreibprozesses mit der Konzeption einer Schreibsituation, welche strategisch als Begrenzung und Formierung des Schreibprozesses dient. Damit ist das zu verwertende Schreibmaterial auf einige Sommermonate, d.h. einige Notizbücher, eingegrenzt: Als Peter Gast bei der Druckmanuskriptherstellung vorschlug, unverwendete Texte aus den Sorrentiner Papieren einzustreuen, antwortete Nietzsche: «Das Sorrentiner M[anu]sc[ript] hat der Teufel geholt; [...] - mir eine Wohlthat, denn solche alten $\mathrm{M}[\mathrm{anu}] \mathrm{sc}$ [ripte] sehen mich wie Schuldner an.» ${ }^{26}$ Unverwendete Notizen erweitern das Material und drängen

24 N. an Fuchs, 20.-27.7.1878, Nr. 736, KGB II 5, S. 340.

25 Stingelin/Thiele 2010, S. 19. Vgl. als prominentes Beispiel dazu Rousseau 1870, S. 200: «Der Anblick der Landschaft, die Reihenfolge angenehmer Bilder, die freie Luft, der große Appetit, das Gefühl von Gesundheit, das ich im Gehen bekomme [...] das alles entfesselt meine Seele, giebt mir größere Gedankenkühnheit, wirft mich, so zu sagen, in die Unermeßlichkeit der Dinge, um sie zu combiniren, auszuwählen, mir anzueignen nach Wohlgefallen, ohne Zwang, ohne Furcht.»

26 N. an Gast, 5.10.1879, Nr. 889, KGB II 5, S. 451; vgl. auch Kap. 2.2.2. Die «Sorrentiner Papiere» bezeichnen eine von Nietzsche an Albert Brenner diktierte Reinschrift auf der Basis der «Pflugschar», vgl. KGW IV 4, S. 103 f. 
auf weitere Verwendung. Die thematische Breite von Gedankensammlungen lässt jedes Notat als potentiellen Text erscheinen. Der Autor Nietzsche tut deshalb gut daran, die Notatmenge möglichst einzuschränken.

3. Umschreiben und Selbstlektüre: Die aufgezeichneten Notate werden dem selektiven Prozess des Umschreibens unterzogen. Nachdem Nietzsche ein Notat in sein Arbeitsheft umschreibt, durchstreicht er dieses im Notizbuch. Nietzsche verwertet sein Notatmaterial. Wie Hoffmann für die Notizbücher von Ernst Mach gezeigt hat, kommt bei solch einer Durchstreichung «die Schleife von Lesen und Schreiben» zu einem vorläufigen Ende. ${ }^{27}$ So gesehen ist die Durchstreichung eine der Haupttechniken, mit denen Nietzsche seine Notizbücher philosophisch verwertet. Auch im Arbeitsheft nutzt Nietzsche eine Technik des vorläufigen Schliessens: Er schreibt am Ende jeder Umschrift drei Kreuzchen hin: «+ ++». Nietzsche lässt gegen oben und unten auch keinen Platz frei, sondern benutzt für Erweiterungen fast nur die leergelassene rechte Heftseite. Dieses Vorgehen zeugt von der Entscheidung, dass die Umschrift vorläufig abgeschlossen ist. Das bestärkt den Textstatus des bereits Geschriebenen, weil es in späteren Schreibschichten im selben Heft nunmehr um Ergänzungen gehen wird, nicht aber um erneutes Umschreiben. Anhand der drei Kreuzchen lässt Peter Gast in der späteren Reinschrift jeweils einen Leerraum zwischen den Abschnitten offen, damit Nietzsche die Textabschnitte zur Herstellung der Zettelstapel auseinanderschneiden kann. Die drei Kreuzchen sind insofern bereits 〈Schnittstellen〉. Und just klassifiziert Nietzsche seine Textabschnitte in dieser Arbeitsphase zum ersten Mal als Aphorismen. ${ }^{28}$ Der Umschreibprozess wird demnach auf das spätere Kompilieren und die Buchherstellung hin ausgerichtet. Dass die Buchform beim Umschreiben bereits antizipiert wird und damit das Notierverfahren durch die Umschriften mit dem Publizieren eng verschränkt ist, zeigt sich beispielhaft im Arbeitsheft M I 2. Dort findet sich nämlich nicht nur ein Arbeitstitel, sondern gestaltete Titelblattentwürfe (Abb. 17 und 26). ${ }^{29}$ Ein Autor, der sein Arbeitsheft mit Titelblattentwürfen beginnt, schreibt offensichtlich für eine Buchpublikation. Das

27 Hoffmann 2008b, S. 208.

28 Vgl. den Hinweis für Peter Gast im Arbeitsheft M I 2, S. 13: «Neuer Aphorismus.!!».

29 Das Entwerfen von Titeln, Titelblättern und Werkplänen bildet ein eigenes Genre in Nietzsches Nachlass. So schreibt Hoffmann über Nietzsches Titelentwürfe: «Denn Nietzsche schreibt die gefundenen Titelphrasen nicht einfach nieder, sondern ordnet sie mittig, analog dem Aussehen eines gedruckten Titelblatts, zusammen mit dem Namen des Autors - seinem eigenen Namen - und manchmal noch durch einen rechteckigen Rahmen abgegrenzt auf den Seiten seiner Hefte an. Offenkundig hängt für ihn die Kraft des Titels, Geschriebenes zu verfügen und Ungedachtes zu entwerfen, an dessen tatsächlicher Nach- oder besser Vorbildung im Notizbuch [...].» (Hoffmann 2008c, S. 55-57) Zu Werkplänen Nietzsches vgl. Röllin 2012. 


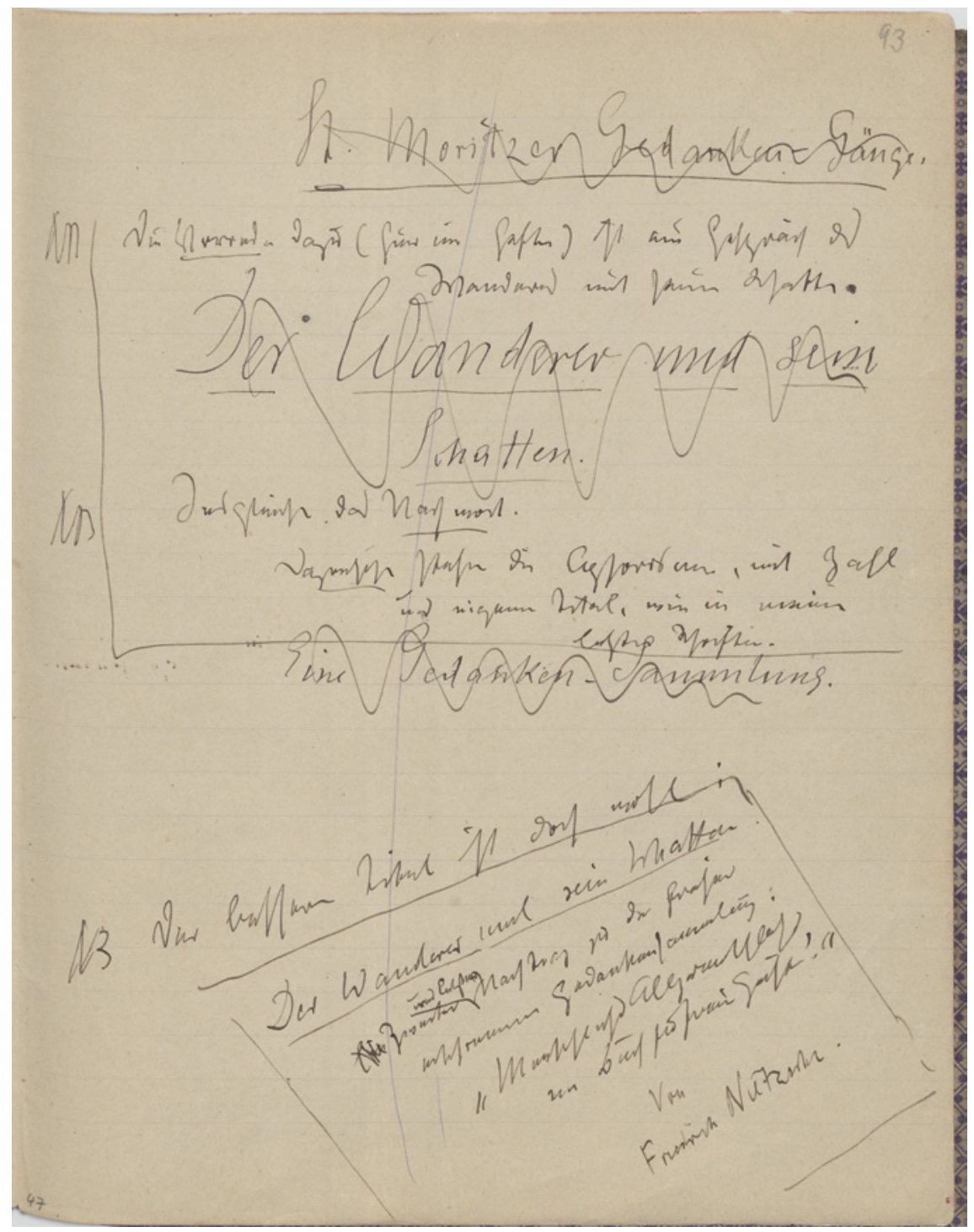

Abb. 26 Titelentwürfe zum Wanderer aus dem Arbeitsheft (M I 3, S. 93) 
Arbeitsheft wird zu einem buchförmigen Manuskript. Auf diese Weise schaffen die Titelblattentwürfe eine Tatsache, - ein Buch - das noch gar nicht existiert. Zum Zeitpunkt der Gestaltung dieser Titelblattentwürfe wussten weder Peter Gast noch der Verleger oder sonst wer von diesem Buch.

4. Reinschreiben und Kompilieren: Die von Peter Gast angefertigte Reinschrift übernimmt wichtige Funktionen der Buchherstellung. Durch die Zusendung seiner Manuskripte an Gast löst Nietzsche die Herstellung des Druckmanuskripts aus. Dieser Prozess strukturiert die ausstehenden Arbeitsprozesse durch zeitliche Termine sowie eine koordinierte Arbeitsteilung. Die Hinweise Gasts (sowie deren Ausbleiben) gaben dem Autor Nietzsche nicht nur ein besseres Textgefühl, sondern auch zusätzliche Gewissheit, dass ein Buch im Entstehen begriffen ist. Dies wird zudem durch die Materialität von Gasts schöner und regelmässiger Handschrift bestärkt, welche annäherungsweise den Eindruck eines gesetzten Textes erweckt. Weil Nietzsche im Wanderer weitgehend auf eine Verwebung seiner reingeschriebenen Zettel verzichtet, ist der Übergang zur Buchherstellung in beide Richtungen fliessend. Das Format des Aphorismenbuchs hat nämlich den Vorteil, dass die Änderung eines reingeschriebenen Aphorismus nicht jene aller anderen zur Folge hat, jedoch den Nachteil, dass die vielen Textabschnitte ohne grossen Widerstand weiter verändert werden können.

5. Drucklegung: Nietzsche kündet das Druckmanuskript bei seinem Verleger erst an, nachdem Gast alle Umschriften reingeschrieben hat. Dies schloss den Verleger von der Manuskriptplanung und -herstellung zunächst aus, liess Nietzsche aber die Möglichkeit offen, die Reinschriften ohne jeden Termindruck auszuarbeiten oder das Druckmanuskript zurückzuhalten. Die DruckmanuskriptAnkündigung ist deshalb die definitive Entscheidung, den Schreibfluss abzuschliessen und sich nunmehr der Drucklegung zu widmen - die Buchherstellung beginnt wie gezeigt schon viel früher. Mit der Zusage Schmeitzners begann ein weiterer arbeitsteiliger Prozess, der auch die Druckerei und einmal mehr Gast einschloss. Ab diesem Zeitpunkt drängt Nietzsche auf eine äusserst rasche Drucklegung. ${ }^{30}$ Nietzsche arbeitet am Wanderer - wie schon an den ersten beiden Aphorismenbüchern - bis zur letzten Minute weiter. Es scheint, als ob sich bei längerem Herauszögern das ganze Zettelmanuskript wieder auflösen und zersetzen könnte. Jeder Tag ohne fertiges Buch provoziert

30 Für die Beschleunigungsbemühungen Nietzsches bei der Drucklegung der Morgenröte vgl. N. an Schmeitzner, 13.3.1881, Nr. 89, KGB III 1, S. 69; für jene bei Jenseits von Gut und Böse vgl. Röllin 2013, S. 48. Bei anderen Autoren kann die Ankündigung auch als Produktionstechnik verwendet werden, indem man erst zu schreiben beginnt, nachdem mit dem Verleger ein Manuskript ausgehandelt ist, vgl. Campe 1991, S. 765. Zur Produktivität von Termindruck und Deadlines vgl. Spoerhase 2018, S. 580-585. 
neue Finessen und Gedanken, die dann umgehend ins Buch hineingedruckt werden müssen. Angesichts des spazierenden Notierens und den dem Schreibakt auferlegten Regeln blieb das entstehende Buch bis zur abgeschlossenen Drucklegung kontingent. Mit einer Woche länger spazieren oder einem Drucklegungstermin im Frühjahr 1880 hätte sich der Wanderer bestimmt verändert und wäre die Morgenröte wohl kaum in der heutigen Form zustande gekommen. Deshalb kann auch für Nietzsche gelten, was Goethe über den beim «Entwerfen und Schreiben» lernenden Winckelmann schrieb: «Daß sie [Winckelmanns Werke] so, wie sie da liegen, erst als Manuscript auf das Papier gekommen, und sodann später im Druck für die Folgezeit fixirt worden, hing von unendlich mannichfaltigen, kleinen Umständen ab.» ${ }^{31}$ Nachdem Nietzsche kurzfristig den Schluss des Druckmanuskripts zu den Vermischten Meinungen änderte, notierte er: «Jetzt ist das Ms abgeschlossen.» ${ }^{32}$ Kurz darauf wurde aber der geänderte Schluss (eine Voltaire-Widmung), durch den heute bekannten Schlussaphorismus «H a de sfahrt» ersetzt. Es ist diesem potenziell unendlichen Änderungsprozess nur mit einer abgeschlossenen Drucklegung zu begegnen, so dass die Schleife rekursiver Bearbeitung aufhört und sich die weiteren Einfälle und Notizen auf neue Buchprojekte richten können. Nietzsche überwand sich zu diesem definitiven Abschluss oft mit Hilfe eines willkürlichen «Trennungsakt[s]».33 So wäre Menschliches laut der Erstausgabe nicht publiziert worden, wenn «nicht die Nähe des 30. Mai 1878», also der 100. Todestag Voltaires, beim Autor den Wunsch einer Veröffentlichung erregt hätte. ${ }^{34}$

6. Nach der Publikation ist vor der...: Nietzsche wollte seine Publikationen überarbeiten und weiterführen. Er beugte jedoch einer Fortsetzung von Menschliches vor, indem er den Wanderer mit der kleingeschriebenen Ergänzung «zweiter und letzter Nachtrag» publizierte. Durch diesen Titelzusatz versucht er eine weitere Fortsetzung zu unterbinden. In der Entwurfsphase hiess es noch «Zweiter Nachtrag», was eine Fortsetzung offenliess. Das Ende kann nur gefunden werden, weil der Autor es in der autorisierten Druckschrift irreversibel festlegt. Das selbstauferlegte Gebot der abgeschlossenen Buchreihe tangiert aber nicht deren Überarbeitung. So plante Nietzsche 1885 eine kom-

31 Goethe 1891, S. 52. Goethe charakterisiert Winckelmann als jemanden, der alles «frisch» verarbeitete und nichts «gähren» liess (ebd.).

32 Druckmanuskript D12, GSA 71/17, Blatt 134, zit. n. KGW IV 4, S. 301.

33 Hurlebusch spricht im Falle der kaum abschliessbaren Arbeiten Goethes am zweiten Teil des Faust von einem notwendig gewordenen willkürlichen «Trennungsakt» (1998, S. 36).

34 Westerdale 2013, S. 59: «Nietzsche claims to publish the book not because it is complete and ready for public consumption, but because of an accident of the calendar.» 
plette Überarbeitung von Menschliches und im Januar 1888 beginnt Nietzsche die ersten drei Aphorismen von Menschliches umzuarbeiten. ${ }^{35}$

Eine solche Aufzählung von Schreibpraktiken kann angesichts der enormen Komplexität einer Schreibsituation nie vollständig sein. Es handelt sich bei dieser Aufzählung um jene Praktiken, die direkt auf den Schreibakt und die Buchherstellung fokussieren. Die Diät, das Kurprogramm, die Landschaft oder das Klima haben als Infrastruktur jedoch eine gleichwertige Wichtigkeit (Kap. 4.3). Die im Wanderer präsentierten Gedanken sind aus Sicht des Autors in den Spaziergängen von St. Moritz aufgehoben und existieren jenseits dieser Schreibsituation nicht. ${ }^{36}$ Für die Autorschaft folgt daraus, dass die materiale Umgebung des Denkens zur philosophischen Arbeit mit dazu gehört. Leben und Schreiben rücken dabei nahe zusammen. Der Ort, an dem sie im philosophischen Schaffen aufeinandertreffen, ist die Schreibsituation. Es wird deshalb für den Philosophen interessant, durch Veränderungen der Schreibsituation sein Denken zu verändern. Die diätetischen und gymnastischen Tätigkeiten interagieren mit der Philosophie. Dies zeigt sich exemplarisch an der konzipierten und inszenierten Schreibsituation im St. Moritzer Sommer 1879.

\subsubsection{Schreibverfahren vs. Aphorismenbuch}

Nietzsches Weg zu seiner Philosophie wird zurecht mit den Aphorismenbüchern in Verbindung gebracht. Der Wechsel zum Aphorismenstil markiert eine Zäsur in seiner Philosophie und erfolgt zur gleichen Zeit wie seine Loslösung von Wagner und Schopenhauer. Darüber hinaus zog sich Nietzsche zunehmend von seiner Professur zurück. Neben diesen biografischen Entwicklungen, gibt es allerdings auch Änderungen in der Produktionsweise: «Vom Jahre 1875 an stehen in seinen Heften (einzelne Blätter verwendet er sehr selten) Gedanken über sämtliche Gegenstände, die ihn interessieren, nacheinander und durcheinander, ohne sachlichen Zusammenhang; dazwischen Pläne, Titel, Dispositionen und anderes.» ${ }^{37}$

Es ist schwierig zu bestimmen, was Nietzsche unter Aphorismen und Aphoristik versteht: Schon ein Jahr nach dem Wanderer fragt sich Nietzsche:

35 Nietzsche wollte 1885 nicht bloss eine Vorrede ergänzen. Die Überarbeitung von Menschliches fiel mitunter darum ins Wasser, weil Nietzsche nicht wusste, dass die Erstauflage zum grössten Teil unverkauft war (Kap. 2.2.4). Für die Umarbeitung vom Januar 1888 vgl. KGW IV 4, S. 164-168.

36 Die Formulierung ist angelehnt an Benne 2015a, S. 539. So wie bei Jean Paul erst im Prozess der Konzeptbildung das Werk und seine Idee enstehen, so ensteht der Wanderer erst in der St. Moritzer Schreibsituation.

Horneffer 1907, S. 647 . 
«Es sind Aphorismen! Sind es Aphorismen? - mögen die welche mir daraus einen Vorwurf machen, ein wenig nachdenken und dann sich vor sich selber entschuldigen - ich brauche kein Wort für mich».38 Für den Wanderer macht die Frage nach der Gattung des Aphorismus wenig Sinn: Nietzsche verstand seine Aphoristik in den Jahren 1878/79 nicht als literarische Gattung, sondern als spezifisches Schreibverfahren zur Produktion von kurzen Texten. ${ }^{39}$ Der Aphorismenstil hängt mit einer veränderten Arbeitsweise zusammen: Noch 1875/76 schreibt Nietzsche mit Hilfe von ausführlichen Schemen die linearen Abschnitte der vierten Unzeitgemässen Betrachtung. ${ }^{40}$

In den Vermischten Meinungen wird die Bezeichnung «Aphorismus» nie benutzt und im Wanderer nur einmal, nämlich als Fremdzuschreibung: «Lichtenberg's Aphorismen». ${ }^{41}$ In Nietzsches Lichtenberg-Ausgabe ist jedoch nur von Bemerkungen und Fragmenten, nicht aber von Aphorismen die Rede. ${ }^{42}$ Lichtenbergs Sudelbücher sind Brouillons, weil sie sich zumindest der Inszenierung nach auf die Entwurfsphase des Schreibens beziehen. Die Idee des Sudelbuchs übernimmt Lichtenberg vom kaufmännischen Waste Book, in das alle Transaktionen eingetragen werden:

Dieses verdient von den Gelehrten nachgeahmt zu werden. Erst ein Buch [sic] worin ich alles einschreibe, so wie ich es sehe oder wie es mir meine Gedanken eingeben, alsdann kann dieses wieder in ein anderes getragen werden, wo die Materien mehr abgesondert und geordnet sind, und der Leidger könnte dann die Verbindung und die daraus fließende Erläuterung der Sache in einem ordentlichen Ausdruck enthalten. ${ }^{43}$

Das Sudelbuch bezeichnet also ein gelehrtes Produktionsverfahren: Zunächst sammelt man all seine Gedanken in einer rohen Form («so wie ich es sehe»). Diese Entwürfe dienen dann wiederum als Material für weitere Umschriften. Wenn Nietzsche unter dem Ausdruck Aphorismen die sudelnde Produktionsweise von lose geordneten Notaten, Kurztexten und Bemerkungen versteht,

$38 \quad$ NL 1880, 7 [192], KSA 9, S. 356.

39 In diesem Sinne datiert Hubert Cancik den Beginn von Nietzsches aphoristischem Schaffen auf das Arbeitsheft M I 1: «Das Heft M I 1 vom September 1876 ist Nietzsches erstes Aphorismen-Buch.» (Cancik 1994, S. 91) Vgl. für die Diskussion über Nietzsches Aphoristik Greiner 1972; Krüger 1988; Spicker 1997, S. 181-204. Nietzsche hatte in den 1870er Jahren noch keine feste Verwendung für «Aphorismus» und sprach zuweilen synonym von Gedanken und Sentenzen (vgl. Krüger 1988, S. 85-98). Dies gilt auch für die Manuskripte von 1879 .

$40 \quad$ Vgl. NL 1875, 14[8], KSA 8, S. 275-277; Montinari 1985.

41 WS 109, KSA 2, S. 599.

42 Vgl. BN, S. $362-364$.

43 Lichtenberg 1968, Bd. 1, E 46, S. 352. 
dann ist das weit entfernt von der aphoristischen «Sentenzen-Schleiferei» der französischen Moralisten. Es geht um das Schreibverfahren, wie ein Kaufmann «von Tag zu Tag» alles einzutragen, «wie ich es sehe oder wie es mir meine Gedanken eingeben». ${ }^{44} \mathrm{Ob}$ man das Produkt dann Aphorismen oder Sudelbücher nennt, ist eine retrospektive Einordnung, die dem spezifischen Schreibverfahren, welches in solchen Manuskripten materialisiert ist, nicht gerecht werden kann. ${ }^{45}$ Diese Hypothese bestätigt sich auch in den Manuskripten und in der Korrespondenz, in denen Nietzsche seine Umschriften und Druckmanuskript-Zettel als «Aphorismen» benennt. ${ }^{46}$ Wie im vorigen Abschnitt dargelegt, bezeichnet Nietzsche im Arbeitsheft M I 2 seine durch Kreuzchen abgetrennten Umschriften zum ersten Mal als Aphorismen. Bei der Manuskriptherstellung und im Wanderer bezeichnen Aphorismen also ein Schreibverfahren.

\subsection{Die Philosophie des Werdens und ihre Werkpolitik}

Nietzsche entwickelt mit seinen Aphorismenbüchern eine Philosophie des persönlichen Werdens, welche den Prozess zwischen den Überzeugungen offenlegen will. Die «Philosophie des Werdens» ist eine häufig auf Heraklit angewandte Bezeichnung. ${ }^{47}$ Sie findet sich erstmals und ausschliesslich in Nietzsches Nachlass vom Januar $1888 .{ }^{48}$ In diesem Kapitel wird mit Philosophie des Werdens jedoch jene Idee aus Menschliches bezeichnet, gemäss der jeder

44 Ebd.

45 In ihrer vergleichenden Studie zu Schriftsteller-Notizbüchern vertritt Svetlana Efimova die These, dass Aphorismen wesentlich auf die Verfertigungsweise zurückzuführen seien: Das Notizbuchschreiben hänge mit den Aphorismen «organisch» zusammen (Efimova 2018, S. 155). Auch Campe versucht für seine Lichtenberg-Studie den Gattungs- und Formdiskussionen auszuweichen, indem er die Spezifität der Sudelbücher in der «Ökonomie der Eintragungen» sieht, «also einer Ordnungsprozedur und -logik, die unterhalb des Begriffs ästhetischer Form liegt.» (2004, S. 89).

46 So etwa in einer Anweisung für Gast im Arbeitsheft M I 3: «Dazwischen stehn die Aphorismen, mit Zahl und eigenem Titel, wie in meinen letzten Schriften» (KGW IV 4, S. 571, Fussnote 129). Ein anderes Mal spricht er in einem Brief an seinen Verleger von Aphorismen (vgl. N. an Schmeitzner, 27.10.1879, Nr. 897, KGB II 5, S. 458f.).

47 Nietzsche war dies vermutlich von den Studien Eduard Zellers bekannt. Im ersten Band seiner Philosophie der Griechen betitelt er das Kapitel über Heraklit, Empedokles und Anaxagoras mit «Philosophie des Werdens» (im Unterschied zur «Philosophie des Seins»), vgl. Zeller 1844, S. 154-244.

$48 \mathrm{KGW}$ IV 4, S. 164. Es handelt sich um eine Umschrift vom ersten Aphorismus von Menschliches, in dessen Kontext die «Philosophie des Werdens» für eine antimetaphysische Philosophie steht, die das Sein leugnet und strikt perspektivisch verfährt. 
Mensch seine Meinungen im Wechselspiel mit seiner Umwelt verändere und die Philosophie diesen Prozess der ständigen Veränderung redlich abbildet. Im Schlussaphorismus von Menschliches bringt Nietzsche seine Philosophie des Werdens in das Bild des Wanderers ohne letztes Ziel, dessen wesentliches Charakteristikum die «Freude an dem Wechsel und der Vergänglichkeit» ist.

Der Wanderer. - Wer nur einigermaassen zur Freiheit der Vernunft gekommen ist, kann sich auf Erden nicht anders fühlen, denn als Wanderer, - wenn auch nicht als Reisender $\mathrm{n}$ a $\mathrm{ch}$ einem letzten Ziele: denn dieses giebt es nicht. Wohl aber will er zusehen und die Augen dafür offen haben, was Alles in der Welt eigentlich vorgeht; desshalb darf er sein Herz nicht allzufest an alles Einzelne anhängen; es muss in ihm selber etwas Wanderndes sein, das seine Freude an dem Wechsel und der Vergänglichkeit habe. ${ }^{49}$

Der Wanderer ohne Ziel steht sinnbildlich für den spazierenden Philosophen, für eine im Arbeitsprozess entstehende Philosophie und für eine Philosophie des Werdens. Für den wandernden Philosophen wird der Weg zum Gegenstand seines Denkens. Die Philosophie des Werdens bringt deshalb keine finalen Gedanken und unverrückbaren Erkenntnisse hervor, sondern Meinungen (4.2.1). Dieses Werden ist kein rein geistiger Prozess, sondern eingebunden in ein Schreibverfahren, das als Versuch einer «Echtzeitphilosophie» gelten kann (4.2.2). Zudem führen Publikationsform und -frequenz der ersten drei Aphorismenbücher performativ zur Philosophie des Werdens (4.2.3). Anhand von zeitgenössischen Reaktionen kann gezeigt werden, dass die Philosophie des Werdens gegen die damalige Vorstellung von philosophischen Buchformaten, Autoren und Publikationsweisen verstiess (4.2.4).

\subsubsection{Dynamische Meinungen und starre Überzeugungen}

Nietzsche präsentiert am Ende von Menschliches über mehrere Abschnitte hinweg sein neues Philosophieverständnis eines unaufhörlichen Wechselspiels von Meinungen und Überzeugungen, das in der Figur des Wanderers kulminiert. Er definiert die Überzeugung als den Glauben, «im Besitze der unbedingten Wahrheit zu sein».50 Dieser Glaube beruht aber nicht auf sorgfältiger Erforschung im Sinne wissenschaftlicher Methoden, sondern auf psychologischen Gründen und Bequemlichkeiten. Seitdem durch die wissenschaftlichen Methoden eine gesunde Skepsis gegenüber Überzeugungen vorbereitet wurde, sei es möglich, etwas «gerecht» zu behandeln. ${ }^{51}$ Die Gerechtigkeit ignoriert al-

\footnotetext{
49 MA 638, KSA 2, S. 362 f.

50 MA 630, KSA 2, S. 356 .

$5_{1}$ Vgl. MA 635, KSA 2, S. 36 of.; MA 636, KSA 2, S. $361 f$. Einmal mehr stellt Nietzsche frühere, zurückgebliebene Epochen dem wissenschaftlichen Geist seiner Zeit gegenüber, vgl. MA 630, KSA 2, S. 356f.; MA 631, KSA 2, S. 357f.; MA 632, KSA 2, S. 358; MA 633, KSA 2, S. $358 f$.
} 
les, «was das Urtheil über die Dinge blendet und verwirrt; sie ist folglich eine Gegnerin der Ueberzeugungen [...].»52 Nietzsche deutet an, dass nach Massstäben der Gerechtigkeit selten die Gewissheit zustande kommt, dass man im Besitz der «unbedingten Wahrheit» ist. Um den Überzeugungen zu entkommen, gibt es nur ein Gegenmittel: ständiges und rastloses Wechseln der Meinungen.

Aus den Leidenschaften wachsen die Meinungen; die Trägheit des $\mathrm{G}$ e is te s lässt diese zu Ueb er z eugun gen erstarren. - Wer sich aber frei en, rastlos lebendigen Geistes fühlt, kann durch beständigen Wechsel diese Erstarrung verhindern; und ist er gar insgesammt ein denkender Schneeballen, so wird er überhaupt nicht Meinungen, sondern nur Gewissheiten und genau bemessene Wahrscheinlichkeiten in seinem Kopfe haben. ${ }^{53}$

Leidenschaften, Meinungen und Überzeugungen sind drei Aggregatszustände desselben Stoffes. Aus gasförmigen Leidenschaften werden flüssige Meinungen, die wiederum zu Überzeugungen erstarren. Der Wechsel gelingt dadurch, dass die kalte Überzeugung im Feuer der Leidenschaften erhitzt wird und auf diese Weise neue Verbindungen eingehen kann. Überzeugungen kann man nicht widerlegen, sondern nur durch verflüssigte Meinungen wechseln. Nietzsche kommt deshalb zum Schluss, dass man anstatt zu einer Überzeugung zu kommen, durch viele Überzeugungen hindurchgegangen sein muss. ${ }^{54}$ Von diesem Stoffwechselhaushalt erleben die rein geistigen Wesen primär den kühlen Bereich. Sie sind «denkende Schneeballen», die gegenüber Leidenschaften und Meinungen kühl bleiben und sich dank «genau bemessene[n] Wahrscheinlichkeiten» auch von den starren Überzeugungen fernhalten. Eine solche Haltung - man denke an das Wissenschaftsideal von Menschliches - ist einerseits ein kunstvoller Balanceakt und andererseits eine bequeme Sicherheit. Denn der Prozess zwischen den Überzeugungen ist mit Leiden, Unsicherheit, Ungewissheit, Unrecht und Kontingenz verbunden. Nietzsche unterscheidet von den kühlen Denkern deswegen die gemischten Denker, welche aus Leidenschaften und Meinungen hervorgehende Überzeugungen durchlaufen und diesen Prozess auf ihre Gerechtigkeit hin prüfen:

$52 \quad$ MA 636, KSA 2, S. 361 .

53 MA 637, KSA 2, S. 362 . In einer weiteren Allegorie stehen Meinungen für Fische und Überzeugungen für Fossilien: «Man ist Besitzer seiner Meinungen, wie man Besitzer von Fischen ist, - insofern man nämlich Besitzer eines Fischteiches ist. Man muss fischen gehen und Glück haben, - dann hat man s e in e Fische, s e in e Meinungen. Ich rede hier von lebendigen Meinungen, von lebendigen Fischen. Andere sind zufrieden, wenn sie ein Fossilien-Cabinet besitzen - und, in ihrem Kopfe, 〈Ueberzeugungen.〉 -» (WS 317, KSA 2, S. 693).

Vgl. MA 632, KSA 2, S. 358 . 
Aber wir, die wir gemischten Wesens sind und bald vom Feuer durchglüht, bald vom Geiste durchkältet sind, wollen vor der Gerechtigkeit knieen, als der einzigen Göttin, welche wir über uns anerkennen. D as Fe uer in uns macht uns für gewöhnlich ungerecht und, im Sinne jener Göttin, unrein; nie dürfen wir in diesem Zustande ihre Hand fassen, nie liegt dann das ernste Lächeln ihres Wohlgefallens auf uns. Wir verehren sie als die verhüllte Isis unsers Lebens; beschämt bringen wir ihr unsern Schmerz als Busse und Opfer dar, wenn das Feuer uns brennt und verzehren will. De $\mathrm{r}$ G e ist ist es, der uns rettet, dass wir nicht ganz verglühen und verkohlen; er reisst uns hier und da fort von dem Opferaltare der Gerechtigkeit oder hüllt uns in ein Gespinnst aus Asbest. Vom Feuer erlöst, schreiten wir dann, durch den Geist getrieben von Meinung zu Meinung, durch den Wechsel der Parteien, als edle Ver rä th e r aller Dinge, die überhaupt verrathen werden können - und dennoch ohne ein Gefühl von Schuld. ${ }^{55}$

Die Philosophie des Werdens bewegt sich an beiden Polen des Temperaturspektrums - mal «durchglüht», mal «durchkältet». In diesem Oszillieren zwischen Leidenschaften und Überzeugungen ist sie zwingendermassen ungerecht, weil das innere Feuer zu unbegründeten Meinungen verleitet, die nach Massstäben der Gerechtigkeit nicht angemessen sind. Der Philosoph ist in solchen Phasen den eigenen Leidenschaften ausgeliefert. Der Geist rettet ihn durch seine Kälte aus diesem Feuer der Leidenschaften: Entweder, indem er den Philosophen vom Feuer wegträgt oder ihn in ein hitzebeständiges Asbest-«Gespinnst» einhüllt, mit dem er sich dem überzeugungszersetzenden Feuer nähern kann. Letzteres ermöglicht dem Denker, anstatt in behäbiger Geistesstarre bei einigen Gewissheiten auszuruhen, weiterhin Meinungen und Parteien zu wechseln. Einmal mehr wird er «durchglüht», um bei der nächsten Abkühlung seine Ansichten verändert vorzufinden. Es geht also gleichsam um den Trick, sich trotz trägem und kaltem Geist ständig zu verändern, ohne dadurch in Überzeugungen zu erstarren. Für Nietzsche sind Meinungen keine oberflächlichen und unausgearbeiteten Gedanken, die er nicht zu Überzeugungen gebracht hat. ${ }^{56}$ Vielmehr ist es für ihn eine Kunst, das lebendige Werden im Aggregatszustand der Meinung einzufangen. Der Titel der Vermischten Meinungen macht dies deutlich. Damit wendet sich Nietzsche einmal mehr gegen die in Menschliches kritisierte Genieästhetik, welche das Werden abweist. ${ }^{57}$

$55 \quad$ MA 637, KSA 2, S. 362.

56 Vgl. auch JGB 289, KSA 5, S. 234, wo ein Einsiedler daran zweifelt, «ob ein Philosoph «letzte und eigentliche> Meinungen überhaupt haben könne, ob bei ihm nicht hinter jeder Höhle noch eine tiefere Höhle liege, liegen müsse [...].»

57 MA 162, KSA 2, S. 152: «Sodann: alles Fertige, Vollkommene wird angestaunt, alles Werdende unterschätzt. Nun kann Niemand beim Werke des Künstlers zusehen, wie es ge worden ist; das ist sein Vortheil, denn überall, wo man das Werden sehen kann, wird 
Der Denker fühlt für seinen ständigen Meinungswechsel keine Schuld. Diese Art von Selbstveränderung wird als Kunststück inszeniert, das trotz allem Verrat als edel gilt. Meinungen sind notwendig mit «Charakter, Beschäftigung, Talent, Umgebung» verflochten, weshalb niemand für sie verantwortlich gemacht werden kann. ${ }^{58}$ Sie bedürfen keiner Legitimation. Es kann nicht von Irrtum oder Verantwortung gesprochen werden. ${ }^{59}$ Der Philosoph ist in seinen Intentionen nicht unabhängig, sondern seine Meinungen ergeben sich notwendig und «unverantwortlich» aus seiner Umgebung und seiner jeweiligen Lebensphase. Deshalb liegt im Wandern ohne Ziel kein teleologisches Motiv, wie es beispielsweise Goethe in Schillers stetiger Veränderung sehen will: «Alle acht Tage war er ein Anderer und ein Vollendeterer; jedesmal wenn ich ihn wiedersah, erschien er mir vorgeschritten in Belesenheit, Gelehrsamkeit und Urteil.»60 Die Philosophie des Werdens löst die persönliche Veränderung ab vom intellektuellen Fortschrittsnarrativ.

Nietzsche legitimiert diese Wechsel, indem er ihnen einen besonderen Grad an Redlichkeit zuspricht. Die durch die Meinungswechsel hervorgerufenen Widersprüche, Ungereimtheiten und Inkonsequenzen bezeugen die Authentizität des Denkens. Es geht um die Redlichkeit gegenüber dem eigenen Werden. So heisst es im Wanderer: «Dass man seine Meinungen wechselt, ist für die einen Naturen ebenso eine Forderung der Reinlichkeit, wie die, dass man seine Kleider wechselt [...].» ${ }^{61}$ Aus diesem Grund plädiert Nietzsche nicht für bestimmte Meinungen, sondern für die Meinungsfreiheit: «Wir würden uns für unsere Meinungen nicht verbrennen lassen: wir sind ihrer nicht so sicher. Aber vielleicht dafür, dass wir unsere Meinungen haben dürfen und ändern

man etwas abgekühlt. Die vollendete Kunst der Darstellung weist alles Denken an das Werden ab; es tyrannisirt als gegenwärtige Vollkommenheit.»

$5^{8}$ Vgl. MA 376, KSA 2, S. 263: «Sieht Einer diess ein und noch dazu, dass alle Meinungen und deren Art und Stärke bei seinen Mitmenschen ebenso nothwendig und unverantwortlich sind wie ihre Handlungen, gewinnt er das Auge für diese innere Nothwendigkeit der Meinungen aus der unlösbaren Verflechtung von Charakter, Beschäftigung, Talent, Umgebung, - so wird er vielleicht die Bitterkeit und Schärfe jener Empfindung los, mit der jener Weise rief: 〈Freunde, es giebt keine Freunde!»»

59 FW 307, KSA 3, S. 544f.: «Jetzt erscheint dir Etwas als Irrtum, das du ehedem als eine Wahrheit oder Wahrscheinlichkeit geliebt hast: du stösst es von dir ab und wähnst, dass deine Vernunft darin einen Sieg erfochten habe. Aber vielleicht war jener Irrthum damals, als du noch ein Anderer warst - du bist immer ein Anderer -, dir ebenso nothwendig wie alle deine jetzigen 〈Wahrheiten〉, gleichsam als eine Haut, die dir Vieles verhehlte und verhüllte, was du noch nicht sehen durftest.» In Also sprach Zarathustra heisst es dann im «Nachtwandler-Lied»: «Alle Dinge sind verkettet, verfädelt, verliebt, - [...].» (Z IV, KSA 4, S. 402).

6o Eckermann 2011, S. 143f.

61 WS 346, KSA 2, S. 701. 
dürfen.» ${ }^{22}$ In Nietzsches Swift-Lektüre findet sich dazu eine pointierte Feststellung: «Wenn einer alle seine Meinungen über Liebe, Politik, Religion, gelehrte Sachen etc. registriren wollte, von seiner Jugend an, und so fort bis in sein hohes Alter, welch ein Bündel von Inconsequenzen und Widersprüchen würde da endlich zum Vorschein kommen!» ${ }^{63}$ In einem auf den Wanderer anspielenden Aphorismus aus der Fröhlichen Wissenschaft ist gar von der «L u st an der Blind heit» die Rede, weil der Wanderer sich nicht für das Ziel interessiere: ««Meine Gedanken〉, sagte der Wanderer zu seinem Schatten, «sollen mir anzeigen, wo ich stehe: aber sie sollen mir nicht verraten, wohin ich gehe. Ich liebe die Unwissenheit um die Zukunft und will nicht an der Ungeduld und dem Vorwegkosten verheißener Dinge zugrunde gehen.»» ${ }^{64}$

Nietzsche verneint eine Verpflichtung des Denkers, seinen früheren Überzeugungen treu zu bleiben. Er versucht darzulegen, dass der Gesinnungswechsel nicht die Ausnahme, sondern im Sinne der Redlichkeit der Normalfall sein müsste.

Sind wir verpflichtet, unsern Irrthümern treu zu sein, selbst mit der Einsicht, dass wir durch diese Treue an unserem höheren Selbst Schaden stiften? - Nein, es giebt kein Gesetz, keine Verpflichtung der Art, wir mü s s e n Verräther werden, Untreue üben, unsere Ideale immer wieder preisgeben. Aus einer Periode des Lebens in die andere schreiten wir nicht, ohne diese Schmerzen des Verrathes zu machen und auch daran wieder zu leiden. ${ }^{65}$

Der Meinungswechsel steht unter Generalverdacht, weil man sich nicht vorstellen kann, aus einer abwägenden Erkenntnis heraus, seine Ansichten zu ändern. Der Philosoph wird deshalb auf unehrenhafte Motive hin verdächtigt, welche seine Meinungsänderung erklärbar machen. ${ }^{66}$ Daran leidet er und muss entweder einigen Schmerz in Kauf nehmen oder sich zum Schweigen entscheiden: «Da macht Jemand als Denker und Mensch eine tiefe schmerzhafte Umwandlung durch und legt dann öffentlich Zeugniss davon ab. Und die Hörer merken Nichts! glauben ihn noch ganz als den Alten!» ${ }^{67}$ Nietzsche geht so weit, dass er Meinungsänderungen nicht als Veränderung des Charakters sieht, sondern vielmehr als Freilegung der vielfältigen Persönlichkeit. So schreibt er in den Vermischten Meinungen: «Veränderte Meinungen verändern

\footnotetext{
62 WS 333, KSA 2, S. 698.

63 Swift 1847, S. 25. Es findet sich auf dieser Seite eine Lesespur, was die Vermutung einer möglichen Lektüre unterstützt.

64 FW 287, KSA 3, S. 528.

65 MA 629, KSA 2, S. 355.

66 Vgl. ebd.

67 WS 246, KSA 2, S. 661f.
} 
den Charakter eines Menschen nicht (oder ganz wenig); wohl aber beleuchten sie einzelne Seiten des Gestirns seiner Persönlichkeit, welche bisher, bei einer andern Constellation von Meinungen, dunkel und unerkennbar geblieben waren.» ${ }^{68}$ Da Nietzsche von «veränderten» Meinungen spricht, kann man folgern, dass «Persönlichkeit» erst im Prozess der Meinungsänderung, d.h. in der Serialität der Meinungen und Gedankensammlungen entsteht.

Die Reinlichkeit gegenüber dem Meinungswechsel, den der Philosoph öffentlich und ohne Scham vollzieht, ist der Vorläufer des ab 1880 aufkommenden Konzepts der «Redlichkeit» in Nietzsches Philosophie. ${ }^{69}$ Es war also unmittelbar nach der Publikation vom Wanderer, als Nietzsche die intellektuelle Redlichkeit zu einem philosophischen Ethos erhob. Wie bereits angedeutet wurde, ist die Redlichkeit an ein Schreibverfahren und an eine Schreibsituation gebunden. Das kann anhand von Jean-Jacques Rousseaus Les Rêveries du promeneur solitaire verdeutlicht werden. Am Anfang der zweiten «Promenades» schreibt Rousseau: «Ich plante also, die allgemeine Befindlichkeit meiner Seele in der jetzigen Situation zu beschreiben [...], und am besten, glaubte ich, gelänge mir dies, wenn ich getreulich die Träumereien protokollierte, die meine einsamen Spaziergänge beleben, kaum dass ich meinen Kopf gewähren und meine Gedanken sich völlig ohne Zwang und Steuerung entwickeln lasse.» ${ }^{70}$ Rousseau verbindet mit den unterwegs entstandenen Gedanken eine höhere Authentizität für die Beschreibung einer momentanen Gefühlslage bzw. «der jetzigen Situation». Diese Authentizität ergibt sich für ihn offenbar durch die beim Spazieren weniger vorhandenen Zwänge und Steuerungen des Autors (man möchte sagen des Bewusstseins). Diese fehlende Kontrolle, die durch die Offenlegung der Schreibsituation unterwegs verbürgt ist, wirkt hier wie ein philosophisches Gütesiegel. Es geht also nicht bloss darum, das Denken in Bewegung zu bringen, sondern darum, ein redliches Abbild des inneren Denkens wiederzugeben. Das ist für Rousseau keine Selbstverständlichkeit, weshalb er zu den Spaziergängen als Technik greift. Leider ist unklar, inwieweit Nietzsche die zitierte Textstelle im Sommer 1879 kennt.

Die Arbeit des Philosophen besteht im Kontrollieren und Auswählen der Schreibsituation. Die sich dabei einstellenden Meinungen müssen durch geeignete Verfahren eingesammelt werden. Dafür wiederum dienen tägliche Spaziergänge, Notizbücher und Bleistifte. Die St. Moritzer Schreibsituation ist die performative Umsetzung der Philosophie des Werdens. Es soll daher in der

$68 \mathrm{VM}_{5} 8, \mathrm{KSA}_{2}$, S. 404.

69 Vgl. für die Emergenz der «Redlichkeit» im Jahr 1880 Brusotti 1997, S. 144-148.

70 Rousseau 2003, S. 19. 
Folge analysiert werden, wie Nietzsche dieses Programm in seiner Arbeitsweise umsetzte.

\subsubsection{Rasche Aufzeichnung und Echtzeitphilosophie}

Die Zeitlichkeit von Produktion und Publikation spielt in der Philosophie des Werdens eine zentrale Rolle. Das Notizbuch und der Bleistift dienen Nietzsche dazu, seine Gedanken rasch aufzuzeichnen und fürderhin als Gedächtnisstütze in Heftform mobil zu versammeln: «Hinterher verliere ich den Zusammenhang der Gedanken aus dem Gedächtniß [...].» ${ }^{71}$ So schreibt er 1877 aus Rosenlauibad:

Nun drängen mich meine Gedanken vorwärts, ich habe ein so reiches Jahr (an innerem Ergebniss) hinter mir; es ist mir als ob die alte Moosschicht täglichen philologischen Nothberufs eben nur abgehoben zu werden brauchte - und alles steht grün und saftig da. Mit Missmuth denke ich daran, dass ich jetzt meine Ausbeute liegen lassen muss, vielleicht die frische Empfindung dafür und damit Alles verliere! Hätte ich doch irgendwo ein Häuschen; da gienge ich wie hier täglich 6-8 Stunden spazieren und dächte mir dabei aus, was ich nachher im Fluge und vollkommener Sicherheit auf's Papier hinwerfe - so habe ich's in Sorrent, so hier gemacht und einem im Ganzen unangenehmen und verdüsterten Jahre viel abgewonnen. ${ }^{72}$

Nietzsches Schreibsituation bedarf bestimmter Lebensumstände. Die Musse des beruflich nicht verpflichteten Kurgastes ermöglicht das tägliche Notieren ohne festes Ziel. Die Freizeit und die Spaziergänge scheinen Nietzsches Gedanken wie einen Katalysator zu befördern. Nietzsche bedauert den Verlust der «frische[n] Empfindung», die seine Gedanken bei ihrem ersten Aufkommen begleitet und die später nicht mehr rekonstruierbar ist. ${ }^{73}$ Er sieht seine Gedanken zeitlich und räumlich in die Schreibsituation eingebunden. Und weil man in jedem Augenblick unterschiedlich denkt, ist es möglich, jeden Tag auf Spaziergängen neue Gedanken zu sammeln. Ein solches Schreiben ist auf den Augenblick bezogen und deshalb selbst ein Wandern ohne Ziel. Die Verbundenheit der Empfindung mit dem Moment bildet als erlebter Augenblick das Material der Philosophie des Werdens.

Nietzsche koppelt durch sein Notierverfahren den Schreibfluss an seine Denkentwicklung, d.h. an Gedanken, Stimmungen und Umgebungen. Er will

$71 \quad$ N. an Gast, 5.10.1879, Nr. 889, KGB II 5, S. 450.

72 N. an Overbeck, 28.8.1877, Nr. 654, KGB II 5, S. 276.

73 Vgl. Kap. 3.1.3. Dies erhellt sich aus Nietzsches Swift-Lektüre: Dort ist folgende Stelle aus einem Brief von Alexander Pope an Swift mit Randstrichen markiert: «daß ein Mensch schwerlich seinen eignen Gedanken zweimal gleich glücklich sagen kann.» (Swift 1847, S. 408). 
die Zeitlichkeit der persönlichen Entwicklung in die Philosophie übersetzen. Deshalb schreibt er seine Notate regelmässig und kontinuierlich in die Quarthefte um. Die Themenvielfalt seiner gesammelten Notizen ermöglicht so eine Momentaufnahme der eigenen Philosophie in einem bestimmten Lebensabschnitt. Ich nenne dieses Phänomen der Kopplung des eigenen Werdens mit der Technik der raschen Aufzeichnung Echtzeitphilosophie. Im Ausdruck «Echtzeit» steckt die Faszination, welche Philippe Lejeune am Beispiel des spazierenden Schriftstellers Pierre-Hyacinthe Azaïs (1766-1845) beobachtet: «Wenn er es bereut, seine Schachtel [mit Schreibzeug] nicht mitgenommen zu haben, dann weniger der Genauigkeit seiner Beschreibung wegen (er hat ein gutes Gedächtnis), sondern wegen des verpaßten Schauers, unmittelbar mit der Zeit verbunden zu sein [...].» ${ }^{74}$ Die Echtzeitphilosophie bedarf aktueller Verbundenheit des Philosophen mit seiner Umgebung. Auch Lichtenberg nutzte die Technik der raschen Aufzeichnung zusammen mit der Datierung. Erst dadurch dokumentieren Manuskripte die geistige Entwicklung. ${ }^{75}$ Wenn Nietzsche Eckermanns Gespräche mit Goethe zu den besten Prosabüchern der deutschen Sprache zählt, so hebt er ein Echtzeitbuch par excellence heraus, das durch das datierte Festhalten von Gesprächsinhalten die Entwicklung und den Denkalltag von Goethe nachverfolgen lässt.

Eine grossgeschriebene Auflistung aus dem Notizbuch N IV 3 enthält in Stichworten zusammengefasst, was Nietzsche durch sein Schreibverfahren betreibt: «Selbst-Entdeckung / Selbst-Abschätzung / Selbst-Veränderung» (Abb. 27). ${ }^{76}$ Diese Notizbuchseite ist ungewöhnlich. Normalerweise achtet Nietzsche in den St. Moritzer Notizbüchern darauf, die mit Bleistift geschriebenen Notate nur dann zu überschreiben, wenn es sich um bereits <verwertete〉 Notate handelt. Im vorliegenden Fall überschreibt Nietzsche die Notizbuchseite mit der Reinschrift des Aphorismus 213. ${ }^{77}$ Während er das unverwendete Notat über die «Würde des Verbrechers» in der Seitenmitte sorgfältig offenlässt, überschreibt er die drei grossgeschriebenen Stichworte mit Tinte. Offenbar handelt es sich bei dieser Aufzeichnung nicht um potenzielles Aphorismenmaterial. Ich interpretiere es als programmatische Anweisung von Nietzsche an sich selbst. Die drei Stichworte gehören mehr dem Notizbuch (und seiner offenen, revidierbaren Form) als der Publikation an. In ihnen ist die Philosophie des Werdens mitsamt ihrer Produktionsweise kondensiert: «Selbst-Entdeckung / Selbst-Abschätzung / Selbst-Veränderung» bilden das

\footnotetext{
$74 \quad$ Lejeune 2010, S. 84.

75 Lichtenberg, J 26, Bd. 1, S. 655. Lichtenbergs datierte Aufzeichnungen fungieren jedoch als teleologische «Signaturen der Fortschritte des Geistes.»

$76 \quad \mathrm{~N} \mathrm{IV}_{3}$, S. 27. Ediert unter NL 1879, 42[33], KSA 8, S. 601.

77 WS 213 , KSA 2, S. 645 f.
} 


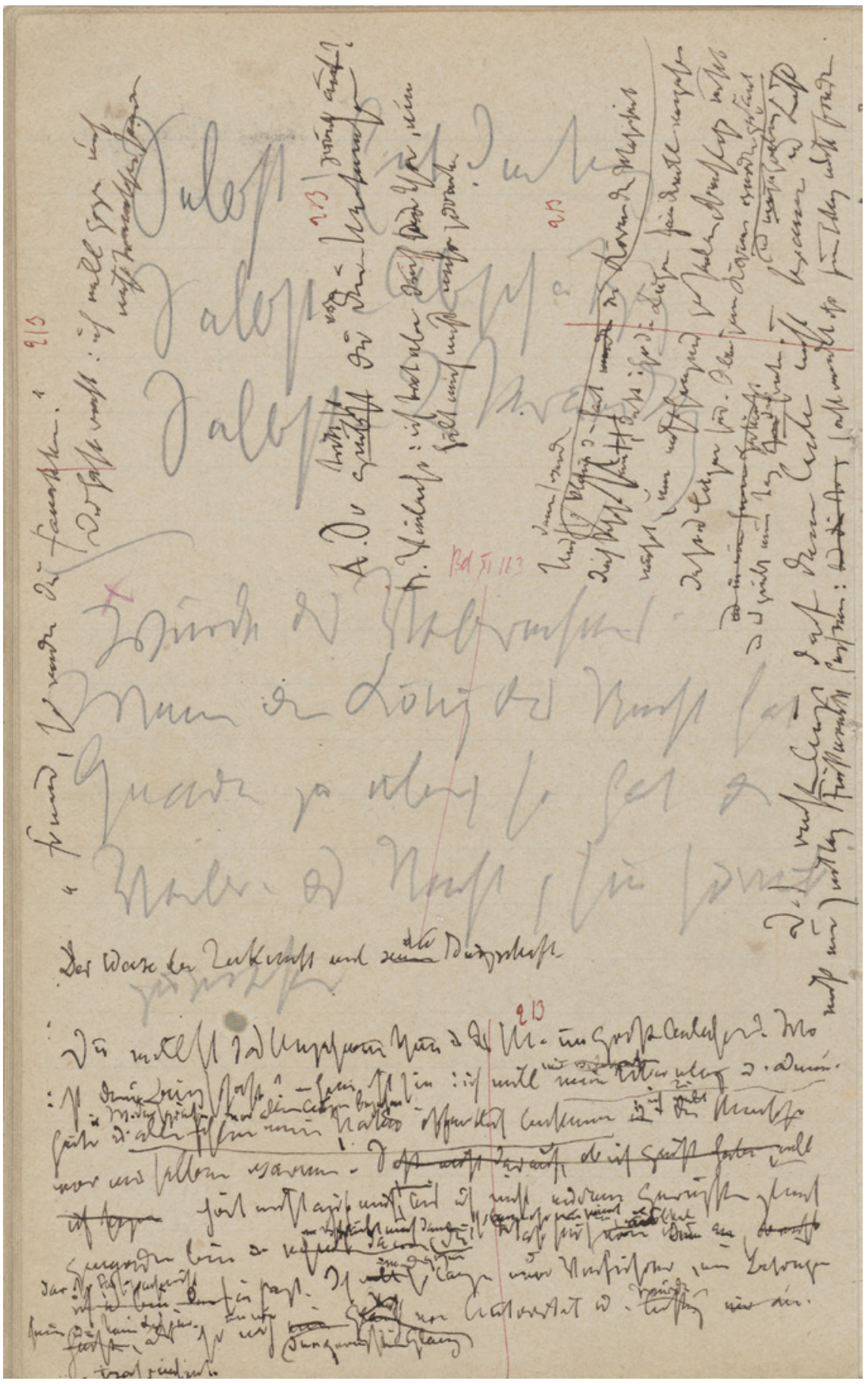

Abb. 27 In der oberen Hälfte der Notizbuchseite, steht die unverwendete und mit Bleistift geschriebene Wortreihe: «Selbst-Entdeckung / Selbst-Abschätzung / Selbst-Veränderung» (N IV 3, S. 27) 
philosophische wie produktive Programm, durch das die Philosophie des Werdens entsteht.

\subsubsection{Dreifach-Publikation und doppelte Werkpolitik}

Es ist in der Folge zu analysieren, inwiefern die Echtzeitphilosophie mit der Publizierpraxis und damit der Werkpolitik zusammenhängt. Denn im Unterschied zum Sudelheft oder Tagebuch schliesst Nietzsche das durch Notieren und Umschreiben gewonnene Material und publiziert eine buchförmige Gedankensammlung. ${ }^{78}$ Die Philosophie des Werdens bezieht sich deshalb nicht nur auf die rasche Aufzeichnung, sondern auch auf die Publikationsfrequenz: Zwischen April 1878 und Dezember 1879 erscheinen in kurzer Folge Nietzsches drei erste Aphorismenbücher: Menschliches (14. April 1878), Vermischte Meinungen (12. März 1879) und der Wanderer (18. Dezember 1879). Rée schreibt angesichts dieser drei Bücher an Nietzsches Mutter humorvoll: «Ihr Herr Sohn hat nun schon dreimal gesprochen und ich habe noch nicht geantwortet». ${ }^{79}$ Da Rée selbst an einem Buch arbeitete, muss es ihm zusammen mit den mehrheitlich von schwerer Krankheit erzählenden Briefen Nietzsches merkwürdig angemutet haben, dass sein Freund in bloss eineinhalb Jahren drei Bücher schrieb und publizierte. Wieso veröffentlicht ein Philosoph kurz nach Erscheinen seines ersten Aphorismenbuchs innert eineinhalb Jahren gleich zwei weitere Schriften in ähnlicher Aufteilung? ${ }^{80}$ Dazu wird in einem ersten Schritt der Zusammenhang zwischen der Dreifach-Publikation und der Philosophie des Werdens geklärt. Danach wird die doppelte Werkpolitik von Nietzsches Philosophie des Werdens erläutert, welche das Zusammenspiel von zeitgenössischen und postumen Strategien sichtbar macht.

\section{Serielles Publizieren}

Die Notizbücher und Spaziergänge sind die Instrumente, das werdende Denken zu erzeugen und festzuhalten, während Aphorismenbücher die geeignete Publikationsform zur literarischen Verdichtung der persönlichen Denkentwicklung sind. Die Publikation scheint zunächst dem werdenden Denken zu widersprechen: Die Drucklegung friert die geschriebenen Gedanken ein und enthebt sie aus dem Prozess der ständigen Veränderung. Nietzsche löst dieses Dilemma dadurch, dass er seriell und rasch publiziert. Erst in seriellen Aphorismenbüchern bilden sich unterscheidbare Lebens- und Denkphasen

\footnotetext{
78 Aphorismenbücher enthalten deshalb keine Tagebucheinträge, sondern zugespitzte, stilisierte und daher notwendig hyperbolische Aphorismen (vgl. Nehamas 2012, S. 55).

79 Rée an Franziska N., 20.12.1879, zit. n. Janz 1978, S. 34.

8o In Menschliches noch als neun Hauptstücke deklariert (vgl. Kap. 2.2.5).
} 
eines Philosophen ab. Die Philosophie des Werdens vollzieht sich zwar in einzelnen Schreibsituationen und daraus hervorgehenden Büchern, sie entfaltet ihr Potenzial jedoch erst in der Differenz verschiedener Aphorismenbücher nebeneinander. Durch die gleichbleibenden Themen lassen sich die zahlreichen Meinungsänderungen, welche sich in den knapp eineinhalb Jahren zwischen Nietzsches erstem Aphorismenbuch Menschliches und dem Wanderer ergeben, nachvollziehen. Nietzsche erlaubt dem Leser durch zugespitzte Momentaufnahmen seines Denkens an seiner Gedankenentwicklung teilzuhaben. Auf diese Weise wird aus der je aktuellen Echtzeitphilosophie die Philosophie des Werdens. Was den unbekannten Schriftsteller Rétif de la Bretonnes (17341806) noch im Rahmen seiner Arbeitsweise interessierte, wird bei Nietzsche zum Publikationsprinzip: «WWas werde ich in einem Jahr, am selben Tag, zur selben Stunde darüber denken?> Diese Idee erregt mich [...].» ${ }^{81}$ Die serielle Dreifach-Publikation nutzt diese Erregung als philosophisches Programm. Es handelt sich bei jedem Aphorismenbuch um den letzten Stand von Nietzsches Philosophie, aber nicht um sein letztes Wort in dieser oder jener Sache. Vielmehr muss der Werdegang von Buch zu Buch brüchig und sprunghaft sein. Erst die Existenz mehrerer Bücher kann die Meinungswechsel des werdenden Philosophen Nietzsche belegen. Sie sind der Beweis für den Status des Werdens, welcher den kohärenten Überzeugungen fehlt. Autorschaft kommt im Wanderer nicht primär über den unverkennbaren Stil oder philosophische Lehren zu Stande, sondern über die veränderten Meinungen. Die fortlaufende Notizproduktion und relativ schnelle Publikation führen performativ zu einer Philosophie des Werdens. Dies wird an einem unverwendeten Entwurf deutlich, der Nietzsches damalige Leser vor den Änderungen in Menschliches warnen sollte:

Lesern meiner früheren Schriften will ich ausdrücklich erklären, daß ich die metaphysisch-künstlerischen Ansichten, welche jene im Wesentlichen beherrschen, aufgegeben habe: sie sind angenehm, aber unhaltbar. Wer sich frühzeitig erlaubt öffentlich zu sprechen, ist gewöhnlich gezwungen, sich bald darauf öffentlich zu widersprechen. ${ }^{82}$

Da Nietzsche seine Gedanken nicht als ein allgemeines Zeugnis der Reife oder Weisheit, sondern als Momentaufnahme eines werdenden Denkens stilisiert, muss er weitere Bücher nachreichen, um vorherige Ansichten zu revidieren und relativieren, unvollständige Denkprojekte weiterzuführen, aber auch, um

81 Rétif de la Bretonnes, Monsieur Nicolas, S. 48of, zit. n. Lejeune 2010, S. 73.

82 NL 1876/77, 23[159], KSA 8, S. 463. Vgl. auch NL 1876/77, 23[156], KSA 8, S. 461f. 
auf ältere Meinungen zurückzugreifen. Auch deshalb muss Nietzsche die Vermischten Meinungen und den Wanderer als Anhang bzw. Nachtrag deklarieren, damit nicht eines dieser Bücher als isoliertes Resultat seines Denkens gelten kann. In diesem Sinne sind Nietzsches drei Aphorismenbücher - und seine weiteren Bücher - als Werdegang zu verstehen.

Die Echtzeitphilosophie synchronisiert Empfinden, Produzieren und Publizieren. Wenn ein Buch publiziert wird, ist der Autor immer schon ein anderer. Es ist nicht verwunderlich, dass Nietzsche nach dem Bruch mit Wagner und Schopenhauer in einer unveröffentlichten Vorrede zu Menschliches Folgendes notiert: «Wenn es schon dem Autor begegnet, dass er, vor sein eigenes Buch hingestellt, demselben mit Befremdung in's Gesicht sieht, und ihm die Frage über die Lippen läuft: bin ich's? bin ich's nicht?» ${ }^{83}$ Aus diesem Grund bespricht Nietzsche in späteren Werken, insbesondere in den Vorreden, seine Bücher als philosophische Verdichtungen von persönlichen Lebensphasen. Nietzsche charakterisiert die Vermischten Meinungen und den Wanderer in der 1886 nachträglich hinzugefügten Vorrede als Überwindungen:

\begin{abstract}
Meine Schriften reden nur von meinen Ueberwindungen: [...] Aber es bedurfte immer erst der Zeit, der Genesung, der Ferne, der Distanz, bis die Lust bei mir sich regte, etwas Erlebtes und Ueberlebtes, irgend ein eigenes Factum oder Fatum nachträglich für die Erkenntniss abzuhäuten, auszubeuten, blosszulegen, «darzustellen» (oder wie man's heissen will). Insofern sind alle meine Schriften, mit einer einzigen, allerdings wesentlichen Ausnahme, zurü ck z u datie re n - sie reden immer von einem «Hinter-mir» -: einige sogar, wie die drei ersten Unzeitgemässen Betrachtungen, noch zurück hinter die Entstehungs- und Erlebnisszeit eines vorher herausgegebenen Buches (der «Geburt der Tragödie» $[\ldots]) .84$
\end{abstract}

Bücher werden in der Relation von «Entstehungszeit» und Publikation eingeschätzt. Das in ihnen Vorgebrachte ist zum Zeitpunkt der Publikation für den Autor Nietzsche nicht mehr aktuell, weil er es bereits überwunden hat - im Falle der Unzeitgemässen Betrachtungen sogar schon vor der Produktion. Da die Aphorismenbücher jedoch nicht der Produktionsweise der Unzeitgemässen Betrachtungen entsprechen, liegt folgender Schluss nahe: Bedenkt man nämlich, dass der Wanderer rasch produziert wurde, dann fallen Erlebniszeit und Publikation beinahe zusammen. Und weil Nietzsche den Wanderer fast nahtlos nach der Publikation der Vermischten Meinungen erarbeitete, schliesse ich, dass es gar keine Reifezeit gibt, die der Buchherstellung wesentlich

\footnotetext{
$83 \quad$ NL 1877, 25[2], KSA 8, S. 483.

84 MA II, Vorrede 1, KSA 2, S. 369 . Vgl. dazu auch Brusotti 1994, S. 445f.
} 
vorausgeht. Vielmehr entspricht der Prozess der Buchproduktion auch jenem der Überwindung.

Die Beschleunigung von Produktion und Publikation zeigt sich im Wanderer in der Forderung, dass Gedanken «unversehens» ein Buch werden sollen: «Ich will keinen Autor mehr lesen, dem man anmerkt, er wollte ein Buch machen: sondern nur jene, deren Gedanken unversehens ein Buch wurden.» ${ }^{85}$ Die Entstehungszeit und die Publikation sollen einhergehen. Eine solche Haltung richtet sich einerseits gegen eine stilisierte Kunstprosa, versucht andererseits aber, eine Authentizität und Redlichkeit gegenüber dem werdenden Denken und der Schreibsituation zu bewahren. Aufgrund der raschen Verarbeitung bleiben die Meinungen durch den Prozess der Drucklegung hindurch möglichst 〈frisch〉 und authentisch. Es kann angesichts von Nietzsches Schreibverfahren und der seriellen Buchherstellung behauptet werden, dass er den scheinbaren Widerspruch zwischen dem beabsichtigten und dem «unversehens» entstandenen Buch durch die St. Moritzer Schreibsituation aufgelöst hat.

\section{Doppelte Werkpolitik}

Mit Werkpolitik werden im Anschluss an Steffen Martus alle Aspekte der Werkinszenierung gemeint, die durch das Aufkommen der Kritik, der Philologie und des Literaturbetriebs entstehen. ${ }^{86}$ Die Anreize, sich mit einem Werk zu beschäftigen, werden gemäss Martus massgeblich vom Buchmarkt, der Kritik und dem Publikum mitbestimmt. Deshalb nimmt ein Autor durch die Präsentationsweise und Inszenierung seines Werks immer schon implizit eine werkpolitische Haltung ein: «das Werk gehört fortan in einen weiten Kontext von Strategien und Taktiken, um ihm Aufmerksamkeit zu verschaffen.» ${ }^{87}$ Martus zeigt insbesondere an Goethe, dass dieser durch seine Werkausgaben, autobiografischen Schriften, Archive etc. eine ihm gewidmete «Goethe-Philologie» anregte, welche in diesen Materialien einen «Autor als Produzenten eines unendlich sinnreichen Werks» entdecken und bearbeiten konnte. ${ }^{88}$ Gefragt

85 WS 121, KSA 2, S. 604.

86 Vgl. allgemein: Martus 2007.

87 Benne 2015a, S. 224.

88 Martus 2007, S. 496. Zum Phänomen des werkpolitischen Kalküls einer literarischen Langlebigkeit vgl. den Begriff der Transaktualität bei Heine/Zanetti 2017 sowie jenen des Nachlassbewusstseins bei Sine/Spoerhase (Hg.) 2017. Neben dem oben bei Martus zitierten Goethe, besass auch Kierkegaard ein ausgeprägtes Nachlassbewusstsein. Joakim Garff zeigt auf, dass Kierkegaard seine «posthumous rebirth» sorgfältigst plante, indem er sein Leben als rätselhaftes und immer weiter zu studierendes Phänomen konzipierte (Garff 2003, S. 113). Kierkegaard beschrieb einen Ekel vor dem Schreiben, der daher rührt, dass man bei der Schreibtätigkeit stets ans Publizieren denkt, vgl. Müller-Wille 20o6. Auch einzelne Werke wie Enten - Eller vervielfachen die Interpretationsmöglichkeiten durch ein 
sind deshalb Strategien der Werkpolitik, durch die «Anschlussmöglichkeiten offeriert werden, in denen die Beurteilungskriterien «gut oder schlecht〉 weniger attraktiv sind als der Unterschied von <interessant oder uninteressant .» ${ }^{89}$ Wenn Nietzsche seine Aphorismenbücher als «interessant, ab er nicht $\mathrm{s} \mathrm{ch} \mathrm{ö} \mathrm{n»} \mathrm{(Kap.} \mathrm{3.2.3)} \mathrm{bezeichnet,} \mathrm{sind} \mathrm{Werkpolitik} \mathrm{und} \mathrm{Philosophie} \mathrm{ineinander}$ verschränkt. ${ }^{90} \mathrm{Um}$ zwischen Strategien der zeitgenössischen und zukünftigen Rezeption zu unterscheiden, wird im Folgenden von einer «doppelten〉 Werkpolitik gesprochen: «Ziel ist es dabei, in jedem Fall - für die gegenwärtigen und künftigen Leser - 〈interessant $\rangle$ zu sein.» ${ }^{91}$ Es geht einerseits um eine kurzfristige Produktions- und Publikationsstrategie, welche das Werden des Denkers in ein Aphorismenbuch überführt, andererseits um ein zukünftiges (allenfalls postumes) Gesamtwerk, das literarische Unsterblichkeit erlangt (Kap. 3.2.1). In Nietzsches Dreifach-Publikation kamen beide Strategien zum Einsatz.

Die kurzfristige Werkpolitik bestand zunächst bloss im Anspruch, in einer Reihe von Büchern die persönliche philosophische Entwicklung redlich zu veröffentlichen. Die Buchherstellung gehörte dabei mit zu den Werkzeugen, um das eigene Werden situativ zu begrenzen und durch eine Publikation abzuschliessen. Nietzsche erste drei Aphorismenbücher sind deshalb wie gezeigt das buchförmige Resultat seiner Echtzeitphilosophie. Doch bereits dieses Unterfangen birgt ein langfristiges Potenzial, welches das je einzelne Aphorismenbuch werkpolitisch verdoppelt: Denn die Dreifachpublikation erlaubt den Lesern, «die Spuren autorschaftlicher Entwicklung» zu entdecken, auszulegen und in Bezug zu anderen Werkphasen zu setzen. ${ }^{92}$ Zugleich erlaubt sie dem Autor, durch nachträgliche Kommentare, Vorreden und Neueditionen, über seine Werke hinweg eigene Narrative zu entwickeln. ${ }^{93}$ Der kalkulierte Umgang mit einem Werkzusammenhang ergab sich insbesondere durch das von den meisten Autoren angestrebte Format einer Werkausgabe: «Einzelwerke werden durch Rückverweise aufeinander bezogen, die Produktion wird als Progression zu verstehen gegeben, Leben und Werk werden als Zusammenhang lesbar

Verweisspiel von Pseudonymen, Autoren, Herausgeber und Textsorten in ein und demselben Buch.

89 Zanetti 2007, S. 737 .

9o WS 126, KSA 2, S. 608.

91 Zanetti 2007, S. 737.

92 Martus 2000, S. 29. Vgl. auch ebd., S. 28: «Die Temporalisierung der Poesie, die Einschreibung einer zeitlichen Dimension in den Text, verleiht ihm Bedeutungstiefe.»

93 Vgl. dazu Martus 200o, S. 27: «Ihre besondere Funktion bekommt die Verbesserungsästhetik im Prozess der Temporalisierung von Poesie, die die Zeit des Autorlebens mit dem Werk in Beziehung setzt.» Nietzsche hat in seinen späteren Vorreden und in Ecce Homo exemplarischen Gebrauch von der Temporalisierung seines Werkes gemacht. 
gemacht, Spätwerke werden als Höhepunkte des Schaffens postulierbar.» ${ }^{94}$ Dies zeigt sich auch beim Wanderer: Die Frage, ob Nietzsche seine Aphorismensammlung als eigenständige Publikation oder als Anhang von Menschliches veröffentlicht, repräsentiert die Problematik der doppelten Werkpolitik: Einerseits will Nietzsche als verhältnismässig junger Autor eine unabhängige Publikation eigenen Rechts, andererseits will er den Werkzusammenhang mit den vorherigen Aphorismenbüchern nicht preisgeben. Der Kompromiss des kleingedruckten Nachtragshinweises auf der Rückseite des Titelblatts zeigt an, dass Nietzsche beide Ansprüche gleichzeitig erhebt. Nietzsches Werkpolitik verläuft deswegen doppelgleisig: Auf der einen Seite die Echtzeitphilosophie mit ihrer Redlichkeit, auf der anderen die Hoffnung auf ein postumes Verweisspiel eines Gesamtwerks mit Phasen, Veränderungen, Widersprüchen und Ambivalenzen; mit revidierten Auflagen, neuen Kommentaren und paratextuellen Eingriffen. Es handelt sich um die Kehrseiten ein und derselben Werkpolitik des Werdens.

Die doppelte Werkpolitik der werdenden Gedanken und der literarischen Unsterblichkeit wird in Nietzsches Vorgehen der nachträglichen Betitelung seiner Zettel ersichtlich. Durch die Betitelung erhalten die Aphorismen eine durch Sperrdruck markierte Bedeutung, die den umgeschriebenen Notaten als solchen nicht beikäme. Während die Aphorismentitel sich erst im kommenden Gesamtwerk und in zukünftigen Generationen gänzlich entfalten, wirken sie auf die zeitgenössischen Leser eitel, ja sogar paradox. So ärgert sich Cosima Wagner darüber, dass Nietzsche in Menschliches einerseits das «Bedürfniss» hatte, «seinen inneren Zustand zu dokumentiren» und andererseits den «Dünkel», «das Betiteln eines jeden, noch so nichtssagenden Satzes». ${ }^{95}$ Damit reagierte sie auf Elisabeth Förster-Nietzsches Beschwichtigung, dass Nietzsche Menschliches in «vollster Harmlosigkeit» geschrieben habe. ${ }^{96}$ Cosima hat die doppelte Werkpolitik der Aphorismenbücher jedoch schon früh erahnt: Neben dem «harmlosen» Bestreben einer dokumentierenden Echtzeitphilosophie, vermutet sie den geheimen «Dünkel», die rasch produzierten Aphorismen mit Bedeutung aufzuladen. Auch wenn Cosima nicht anerkennt, dass es durchaus auch Qualität sein könnte, die Nietzsches Strategien erfolgreich machen würden, so hat sie doch die Ambivalenz der doppelten Werkpolitik wahrgenommen.

Nietzsches doppelte Werkpolitik erfüllt sich dann, wenn die publizierten Bücher in einen konstanten Werdensprozess geraten, auf immer neue Weise

94 Zanetti 2012, S. 47.

95 Cosima Wagner an Elisabeth N., 9.3.1879, zit. n. KGW IV 4, S. 63 und 65.

96 Ebd., S. 63. 
gelesen, ausgelegt und weitergeschrieben werden: «Das glücklichste Loos hat der Autor gezogen, welcher [...] in seinen Schriften noch fortlebe und dass er selber nur noch die graue Asche bedeute, während das Feuer überall hin gerettet und weiter getragen sei.» ${ }^{97}$ Der Geist des Autors legt Feuer in Form von Büchern. Während er sich von ihnen durch Abkühlung losreisst, brennen diese weiter und entzünden sich an den Lesern. Sowie der Autor durch das Schreiben anderer Bücher weiterlebt, tut es das Buch durch das Gelesenwerden. Es suche «sich seine Leser, entzündet Leben [...] kurz: es lebt wie ein mit Geist und Seele ausgestattetes Wesen und ist doch kein Mensch.» ${ }^{98}$ Das gut geschriebene und stets wiedergelesene Buch führt ein Eigenleben. Im Akt der Publikation löst es sich vom Schriftsteller. Zurück bleibt jedoch der Autorname, während der dem persönlichen Werden unterliegende Autor sich weiter verändert - bis er auf die Dauer an diesem Prozess verkohlt und als Asche zurückbleibt. Nietzsche besass schon früh die feste Überzeugung, dass das Persönliche die Zeit überdauern könne. Es überlebe nämlich die Systeme, es sei das «ewig Unwiderlegbare». ${ }^{99}$ Diese Möglichkeit behauptet Nietzsche im Wanderer auch für Rousseau: «Sucht man nach den Quellen dieses Stromes: so findet man einmal Rousseau, aber den mythischen Rousseau, den man sich nach dem Eindrucke seiner Schriften - fast könnte man wieder sagen: seiner mythisch ausgelegten Schriften - und nach den Fingerzeigen, die er selber gab, erdichtet hatte (er und sein Publicum arbeiteten beständig an dieser Idealfigur).» ${ }^{100} \mathrm{Mit}$ zunehmender zeitlicher Distanz steigt deshalb die «schöpferische[ ] Kraft der Persönlichkeit und die daraus entstehende persona». ${ }^{101} \mathrm{Zu}$ Lebzeiten ist diese «persona» jedoch noch nicht ausgebildet, und nur zu gerne werden Autorpersönlichkeit und Privatperson von der Kritik aufeinander bezogen. Deshalb

$97 \quad$ MA 208, KSA 2, S. 171.

98 Ebd.; und weiter: «Jeden Schriftsteller überrascht es von Neuem, wie das Buch, sobald es sich von ihm gelöst hat, ein eigenes Leben für sich weiterlebt; es ist ihm zu Muthe, als wäre der eine Theil eines Insectes losgetrennt und gienge nun seinen eigenen Weg weiter. Vielleicht vergisst er es fast ganz, vielleicht erhebt er sich über die darin niedergelegten Ansichten, vielleicht selbst versteht er es nicht mehr und hat jene Schwingen verloren, auf denen er damals flog, als er jenes Buch aussann [...].»

99 PHG, KSA 1, S. 803. Es war schon die Überzeugung des frühen Nietzsches, dass eine Sprechweise oder ein Stil einer Person entspreche. Vgl. NL 1871, 9[73], KSA 7, S. 301: «Die Personen und die Versformen entsprechen sich.» Vgl. auch NL 1882, 3[1], KSA 10, S. 89: «296. Das Verständlichste an der Sprache ist nicht das Wort selber, sondern Ton, Stärke, Modulation, Tempo, mit denen eine Reihe von Worten gesprochen werden - kurz die Musik hinter den Worten, die Leidenschaft hinter dieser Musik, die Person hinter dieser Leidenschaft [...].» Zum Topos des Stils als Persönlichkeit vgl. Müller 1981, S. 40-51.

100 WS 216, KSA 2, S. 651.

101 Benne/Müller 2014, S. 36. 
hat Nietzsche die Freunde des Autors als schlechteste Leser bezeichnet und in den Vermischten Meinungen beklagt, dass der «Name des Autors auf dem Buche» dafür verantwortlich sei, dass «Bücher so wenig wirken». Und weiter: «sobald aber der Autor sich durch den Titel zu erkennen giebt, wird die Quintessenz wieder von Seiten des Lesers mit dem Persönlichen, ja Persönlichsten diluirt, und somit der Zweck des Buches vereitelt.»102 Darin mag ein Grund liegen, weshalb Nietzsche im Rückblick auf seine Denkphasen biografisch schreibt (Ecce Homo), jedoch während seinen ersten Aphorismenbüchern (bei den Arbeiten am Wanderer etc.) immer wieder biografische Bezüge tilgt. So etwa die Änderung des Arbeitstitels «St. Moritzer Gedanken-Gänge» oder die vielen getilgten Ich-Formulierungen. Des Weiteren zeigt sich hier auch Nietzsches werkpolitischer Anspruch, dass seine Schriften literarisch langlebig (d.h. zyklisch lesbar und vielfältig auslegbar) sein sollten. Im Akt des Gelesenwerdens kann der Autorname unabhängig weiterleben. Für dieses Ziel wirken der empirische Autor und die biografische Schreibsituation hemmend. Damit ist vorweggenommen, was man gewöhnlich mit Ecce Homo verbindet, nämlich die Möglichkeit eines Autorlebens nach Ablauf der persönlichen Lebenszeit: «Ich selber bin noch nicht an der Zeit, Einige werden posthum geboren.» ${ }^{103} \mathrm{Zu}$ diesem Schluss gelangen auch Christian Benne und Enrico Müller:

Ecce homo ist nur die konsequenteste Ausprägung einer Entwicklung, die seit Der Wanderer und sein Schatten Gestalt findet. Seit dieser Schrift nimmt nicht nur Nietzsches Auseinandersetzung mit den Personen anderer Denker und Künstler zu, die scheinbar immer weiter von der 〈inhaltlichen〉 Auseinandersetzung mit 〈Positionen〉 wegführt, sondern er beginnt, nachdrücklich die eigene Autorschaft zu stilisieren, in der Nietzsche als Autor nicht mehr als «sich〉 selber, sondern als «Nietzsche» einer Autor-Persona spricht, deren Persönlichkeit allenfalls zu erraten wäre. ${ }^{104}$

Dieser Befund kann dahingehend präzisiert werden, dass Nietzsche sich nicht bloss vermehrt mit Personen, sondern mit persönlichen Arbeitsweisen und ihren Wechselwirkungen auf die jeweilige Philosophie oder Kunst auseinandersetzt. Nietzsches «Autor-Persona» hebt sich vom Autor Nietzsche nämlich vor dem Hintergrund der inszenierten Schreibsituation ab. Der werdende Autor ist immer schon weiter gewandert, wenn die Leser die Stimme seiner «Autor-Persona» vernehmen.

\footnotetext{
102 VM 156, KSA 2, S. 442f.

103 EH, KSA 6, S. 298. Vgl. Brücker 2014.

104 Benne/Müller 2014, S. 53.
} 


\subsubsection{Zeitgenössische Reaktionen}

Nietzsches Philosophie des Werdens konfligiert mit den philosophischen Normen der Weisheit, Reife, Kontinuität und Kohärenz. Zeitgenössische Leser und Freunde fühlen sich durch Nietzsches stetigen Meinungswechsel empfindlich gestört. Das Verhältnis von Autor und Werk stellte sich nach dem radikalen Bruch mit Schopenhauer und Wagner dringlicher als je zuvor in Nietzsches Leben. Es entbehrt nicht ganz der Ironie, wenn Nietzsche die Aufzeichnungen von raschen Meinungswechseln 1876 als negative Kritik formuliert und gleichzeitig das zeitliche Modell seiner zukünftigen Philosophie vorwegnimmt: «Je schneller der Umschwung der Meinungen erfolgt, umso schneller läuft die Welt, die Chronik verwandelt sich in das Journal, und zuletzt stellt der Telegraph fest, worin in Stunden sich die Meinungen der Menschen verändert haben.» ${ }^{105}$ Diese Kritik ist nahe an jener von Nietzsches Freunden und Zeitgenossen, die ihm angesichts seiner ersten drei Aphorismenbücher vorwarfen, dass er zu rasch seine Ansichten publiziere und zu sehr dem Willen zur Neuigkeit unterliege.

\section{Philosophische Buchformate}

Die Eigenheiten der Philosophie des Werdens und der Aphorismenbücher verdeutlichen sich vor dem Hintergrund der zeitgenössischen Vorstellung von philosophischen Büchern. Meinungen gehören wie Entwürfe oder Skizzen zum Prozess des Werdens. In ihnen ist der denkerische Prozess noch nicht abgeschlossen. Die Hervorhebung der Meinung gegenüber der Überzeugung untergräbt das Philosophieverständnis des deutschen Idealismus. Gemäss Hegel gehören Meinungen nicht zur Philosophie: «Eine Meinung ist eine subjektive Vorstellung, ein beliebiger Gedanke, eine Einbildung, die ich so oder so, und ein anderer anders haben kann; [... es gibt keine philosophischen Meinungen.»106 Hegel schliesst Schreibverfahren und Publikationsformen, die nicht auf die allgemeine Stimmigkeit des Geschriebenen Wert legen, von

105 NL 1876, 19[89], KSA 8, S. 352. Nicht mehr das, was philosophisch wahr ist, sondern das, was aktuell in den eigenen Gedanken vor sich geht, wird zum Kriterium der Publikation. Nietzsches erste Aphorismenbücher könnte man in diesem Sinne humorvoll als persönliche 〈Jahreszeitung bezeichnen.

106 Hegel 1994, S. 18 (zit. n. der Synopsis der verschiedenen Manuskripte zur Vorlesung über die Geschichte der Philosophie). Vgl. auch den Unterschied von Sentenzen und Meinungen: «Vergleicht man die Sinnzusammenhänge von «Sentenz〉 und «Meinung», dann bezieht sich 〈Sentenz〉 auf die in äußerster Anstrengung und Besonnenheit gewonnene Form der Aussage, die 〈unvergänglich ist inmitten des Wechselnden〉, wogegen «Meinung〉, auf den Inhalt bezogen, Veränderung und Wechsel mit einschließt.» (Krüger 1988, S. 92). 
vornherein aus der Philosophie aus. Damit reiht er sich in den historisch weit zurückreichenden Diskurs von Büchern als Systeme oder Aggregate ein. ${ }^{107}$

Für die deutschsprachige Philosophie wurde die Vorstellung des Buchs als System massgeblich durch Kant geprägt. Seine Unterscheidung von System und Aggregat macht Kant aufgrund der Zeitlichkeit, in der sich die Teile und das Ganze formieren: «Ferner aber müssen wir auch die Gegenstände unserer Erfahrung im Ganzen kennen lernen, so daß unsere Erkenntnisse kein Aggregat, sondern ein System ausmachen; denn im System ist das Ga nz e eher als die Theile, im Aggregat hingegen sind die The ile eher da.» ${ }^{108} \mathrm{Im}$ Unterschied zum «gehäuft[en]» Aggregat, sei das System durch einen vorgängigen Plan «gegliedert».109 Auf philosophische Bücher übertragen, darf im Falle eines Systems also kein Teil überflüssig oder zufällig sein. Nur so kann der Philosoph nachweisen, dass er ein «systemförmiges Wissen» besitzt. ${ }^{110}$ Ein Buch erscheint auf diese Weise als Resultat der Niederschrift eines vorgängig erarbeiteten Plans, der unabhängig von den Schreibprozessen existiert.

Auch Schopenhauer orientierte sich am Kant'schen Buchideal, als er von sich behauptete: «Bei mir Widersprüche zu suchen ist ganz eitel: Alles ist aus Einem Guß.» ${ }^{111}$ Schopenhauer inszeniert sich als Gegenpol zu einer dynamischen, wechselnden und werdenden Philosophie. Ein Philosoph soll ausschliesslich «die fertigen [...] Gedanken» kommunizieren. Stephan Kammer hat diese Produktionsästhetik sorgfältig analysiert: «Seinem metaphysischen Anspruch nach ohnehin, aber auch seiner Selbstinszenierung als Philosophie zufolge darf Schopenhauers philosophisches OEuvre gerade eines nicht sein: ein Wissen im Entwurf, das von den Verfahren des Aufzeichnens und Notierens allererst hervorgebracht wird.» ${ }^{12}$ Deshalb fordert Schopenhauer, dass man ihn vollständig gelesen haben muss, was werkpolitisch nur aufgrund einer Gesamtausgabe möglich ist. ${ }^{113}$ Nietzsches erste drei Aphorismenbücher zeugen indes vom genauen Gegenteil: So bildet Menschliches einen Bruch mit Nietzsches früherer Philosophie, während von Buch zu Buch weitere Verände-

107 Für die durch System und Aggregat strukturierten Vorstellungen des philosophischen Buches vgl. Spoerhase 2018, S. 459-478, bes. S. 464 f.

108 Kant, AA, Bd. IX, S. 158.

109 Kant, AA, Bd. III, S. 539.

110 Spoerhase 2018, S. 479. Dies belegen auch die zahlreichen Formen «expositorischer Prosa», in denen die Pläne von den Autoren dargelegt, skizziert oder angekündigt werden (ebd., S. 482).

111 Schopenhauer an Johann August Becker, 31.3.1854, Nr. 323, in: Schopenhauer 1978, S. 336.

112 Kammer 2010, S. 29.

113 Vgl. ebd., S. 31f. Freilich klaffen Buchideal und Schreibpraxis bei Schopenhauer weit auseinander, weil viele seiner Bücher einem «permanenten Entwurfsprozess» unterliegen (vgl. ebd., S. 37). 
rungen publiziert werden. Die Kohärenz philosophischen Denkens steht nicht mehr im Mittelpunkt, vielmehr erklärt Nietzsche sie zum Zeichen einer Erstarrung. Schopenhauers Inszenierung der vollständigen Bücher und Gesamtwerke, die man nur genau genug zu lesen brauche, wird hier eine Absage gemacht.

In diesem Sinne bezeichnet Cosima Wagner Nietzsches erstes Aphorismenbuch Menschliches als «kindisch» und «oberflächlich», weil «Aphorismen beinahe einem Jeden gelingen, während das Bedeutende eines Buches eben in dem Zusammenhang besteht.»114 Der materiale Charakter des Buches macht auf Cosima Wagner keinen Eindruck, weil für sie der Zusammenhang «das Bedeutende eines Buches» ausmacht. Das ist die Buchvorstellung Kants sowie die Werkpolitik Schopenhauers, der am Grossteil der Autoren kritisiert, dass sie nicht wüssten, was die «Folge und der Zusammenhang ihrer Sätze» sei: «Viele wissen selbst dies nicht, sondern schreiben, wie die Korallenpolypen bauen: Periode fügt sich an Periode, und es geht wohin Gott will.»115

Aphorismenbücher sind keine philosophischen Abhandlungen, die sich durch systemförmiges Wissen auszeichnen. Doch auch Aggregate können verschiedene Ordnungsformen hervorbringen oder nachträglich systematisiert werden. ${ }^{116}$ Aphorismenbücher beweisen keineswegs, dass Nietzsche keine Systeme hatte oder chaotisch arbeitete. ${ }^{117}$ Nietzsche verschob die Systematik von der Buchform zur Schreibsituation. Das Aphorismenbuch, wie Nietzsche es mit dem Wanderer vorlegt, ist eine Publikationsform, die es ermöglicht, ohne systematischen Plan, jedoch mit einer systematischen Infrastruktur, der Schreibsituation, Bücher zu schreiben (Kap. 4.3).

\section{Redlichkeit vs. Kontinuität}

Nietzsches Redlichkeit des Werdens überzeugt bei weitem nicht alle Zeitgenossen. Das Problem ist nicht der Wandel und die Veränderung an sich. Es ist

\footnotetext{
114 Cosima Wagner an Elisabeth N., 9.3.1879, zit. n. KGW IV 4, S. 63.

115 Schopenhauer 1976, S. 642.

116 Nietzsche gliedert und betitelt beispielsweise seine Aphorismenzettel nachträglich. Zudem erzeugt eine Aphorismensammlung in gedruckter Buchform das Bewusstsein eines Ganzen und weitere Ordnungsmuster, die sich aus der blossen Reihung, Nummerierung, dem Layout und dem Einband ergeben. Vgl. zur Materialität des Buchartefakts Spoerhase 2018, bes. S. 505-508.

117 Vgl. ebd., S. 517. Schlegel erkannte zwar die Dynamik von Philosophien, die sich über das Werden konstituieren. Er statuiert jedoch einen unnötigen Gegensatz zwischen Systemen und werdenden Philosophien: «Plato hatte kein System, sondern nur eine Philosophie; die Philosophie eines Menschen ist die Geschichte, das Werden, Fortschreiten seines Geistes, das allmähliche Bilden und Entwickeln seiner Gedanken. Erst dann, wenn er mit seinem Denken fertig und zu einem bestimmten Resultat gekommen ist, entsteht ein System.» (Schlegel 1958, S. 118).
} 
die sprunghafte Publikation all dieser Veränderungen, welche Missgunst und Ärger erzeugt. Einen lebendigen Eindruck der zeitgenössischen Irritation gibt Johannes Volkelt, Philosoph und später Professor in Basel. Er hatte sich als Habilitand gerade erst von Hegel zu lösen begonnen und hörte nun von Paul Rée, dass die ihn aufwühlenden und faszinierenden Schriften Nietzsches nur eine «Periode» gewesen sein sollen. ${ }^{118}$ Wie Volkelt betont, kam es ohne «Übergangsschrift» von den Unzeitgemässen Betrachtungen zu Menschliches. Auch im Sommer 1879 macht Nietzsche die Erfahrung, dass ihm Leser der Unzeitgemässen Betrachtungen schreiben. Da sie teilweise noch keine Kenntnis von Nietzsches Wandel hatten, sprechen sie ihn als Autor einer Werk- und Denkphase an, die Nietzsche hinter sich gelassen hat. Da Menschliches aber das erste Dokument des öffentlichen Bruchs ist und die oben beschriebene Philosophie des Werdens das Buchende dieses Dokuments bildet, kann letztere als philosophische Legitimation verstanden werden, welche die Reaktionen, die Kritik und die persönlichen Vorwürfe antizipiert. ${ }^{19}$

Erwin Rohde schrieb im Mai 1879 an Franz Overbeck, also just nach der Lektüre der Vermischten Meinungen, dem zweiten und loser angeordneten Aphorismenbuch, folgende Zeilen:

\begin{abstract}
Ob es freilich recht ist, alle diese Wandlungen nun gleich vor dem Publicum zu vollziehen, ist zweifelhaft: ganz naturgemäß verliert, wer allen solchen Wegen folgt, das rechte Vertrauen zu einem Geiste der mit solcher Virtuosität alle möglichen Standpuncte nach Belieben einnehmen kann und sich dessen noch rühmt, was unsereiner als einen Mangel empfindet, nämlich der Freiheit von jenem Zwange, die Welt in einer ganz bestimmten Beleuchtung zu sehen, welcher vom Talent das Genie so gut wie freilich auch den Dummkopf unterscheidet. ${ }^{120}$
\end{abstract}

Da sich Rohde auf die Vermischten Meinungen bezieht, die er im Vergleich zu Menschliches inhaltlich besser findet, sind auch jene «Wandlungen» zwischen den ersten zwei Aphorismenbüchern gemeint. Rohde nimmt Anstoss an der Veröffentlichung von persönlichen Veränderungsprozessen. Was Nietzsche als Kunststück inszeniert, durch das Einnehmen von «allen möglichen Standpunkten», ist für Rohde ein Mangel. Offenbar sollten für Rohde solche persönlichen Veränderungen zunächst privat geschehen, wie es wohl in den meisten Fällen früherer Philosophie geschah (allein schon der Buchherstellungsdauer wegen). Rohde unterscheidet also sorgfältig zwischen öffentlichem Autor und Privatperson. Erst durch die umgehende Veröffentlichung von Nietzsches

\footnotetext{
118 Volkelt 1926, zit. n. Krummel 1998, S. 6o.

119 Zur Thematik der zunehmenden Antizipation von Kritik und Erwartungshaltungen durch die Autoren vgl. Zanetti 2012, S. 48f.

120 Rohde an Overbeck, 31.5.1879, Nr. 17, in: Overbeck/Rohde 1990, S. 34.
} 
«Wandlungen» verliert der Autor das Vertrauen seines Publikums. Durch dieses wegfallende Vertrauen gerät Nietzsche in ein diffuses Feld der Zuordnungen zwischen Genie und Dummkopf. Es ist feinsinnig, dass Rohde mit dem Virtuositätsvorwurf eine Facette der Genieästhetik anspricht, die Nietzsche in Menschliches bekämpft. Was Rohde freilich nicht versteht oder ablehnt, ist der Publikationsakt als Teil der Philosophie. Nietzsche nutzt die Publikation als Mittel der Veränderung und Überwindung. Die Selbstbildung wird performativ über und durch das Publizieren realisiert.

Auch das Nacheinander von Perspektiven, die ein Philosoph des Werdens durchläuft, hat Rohde aufmerksam an Nietzsches rascher Verarbeitung von Adalbert Stifters Nachsommer bemerkt und kritisiert. Während Rohde und seine Frau an Stifters Buch zurückdenken und den Nachgeschmack als «das eigentliche Kriterium eines Buches» gelten lassen, «macht N[ietzsche] diese Art sofort zur einzigen, die noch gelten soll, aus dem Einen gelungenen Wurf wird sofort eine Regel, nach der man nun Alles fordern und beurtheilen soll!! ${ }^{121}$ Diese Kritik unterstellt dem freigeistigen Philosophen einen Hang zur Dogmatik (zu erstarrten Überzeugungen), freilich mit der besonderen Eigenart der Philosophie des Werdens, die Dogmen sehr schnell zu wechseln. Rohdes Kritik als Zeitgenosse, der die drei Aphorismenbücher nacheinander (und nicht als Teil einer Gesamtausgabe) las, lässt eine ärgerliche Sprunghaftigkeit von Nietzsches Büchern erahnen. Diese ist auf die zugespitzten Aphorismen zurückzuführen, welche im Drucktext übertrieben und beinahe dogmatisch wirken. Auch Cosima Wagner enervierte sich in ihrer Kritik an Menschliches über das Publizieren von Übergangsstadien: «Von seinen Werken zu sagen (was höchstens Andere und nach geraumer Zeit sagen könnten) meine Schriften sind Entwicklungsstufen, ist gar seltsam; ungefähr wie wenn Beethoven gesagt hätte: ich schreibe jetzt in meiner dritten Manier.» ${ }^{122}$ Die Pointe der Philosophie des Werdens liegt jedoch wie angedeutet darin, das Provisorische und Unausgereifte als Teil der Philosophie zu verstehen, sofern es erstens stilisiert und zweitens in seriellen Publikationen weiterhin verändert und umgedeutet wird. Nietzsche hat sein Werden zum Resultat gemacht. Seine Echtzeitphilosophie kümmert sich nicht darum, ob «Andere und nach geraumer» Zeit seinem Denken eine Veränderung zugestehen. Cosima Wagners und Rohdes Kritik liegt heute verschollen unter Nietzsches erfolgreicher Werkpolitik, welche durch das Fortschreiben der jeweiligen Meinungen eine Latenzzeit in Kauf nahm,

\footnotetext{
121 Ebd., S. 35 .

122 Cosima Wagner an Elisabeth N., 9.3.1879, zit. n. KGW IV 4, S. 65. Konsequenterweise kommt sie zum Schluss: «[...] den Autor dieses Werkes kenne ich nicht, [...].» (ebd., S. 62).
} 
die mit zunehmenden Publikationen und Werkausgaben in einem anregenden Verweisspiel eines dynamischen Denkens resultierte.

Nietzsche konnte das Dilemma zwischen dem dynamischen Denken und den mit dem Publizieren verbundenen Lesererwartungen 1879 noch längst nicht zufriedenstellend lösen. Am 5. Oktober schreibt er an Peter Gast:

In Ihrem Lebensalter trieb ich mit größtem Eifer Untersuchungen über die Entstehung eines Lexikons des 11. Jahrhunderts post Chr. und über die Quellen des Laertius Diogenes und hatte keinen Begriff von mir, als ob ich ein Recht hätte, eigne allg e m ein e Gedanken zu haben und gar vorzutragen. Noch jetzt überfällt mich das Gefühl der kläglichsten Neulingschaft; mein Alleinsein, mein Kranksein hat mich etwas an die 〈Unverschämtheit meiner Schriftstellerei gewöhnt. Aber, An de re müssen alle s besser machen, mein Leb en sowohl als mein Denken..$^{123}$

Nietzsches Feststellung der «kläglichsten Neulingschaft» und des Zweifels an seinem Rechte, allgemeine Gedanken niederzuschreiben, zeugen vom Leiden an der eingangs zitierten akademischen Werkpolitik. Zudem gewinnen die ephemeren Gedanken einer Spazier-Existenz durch die Verschriftlichung einen allgemeinen und zeitlosen Anspruch, der diesen Gedanken in ihrem Alltagskontext nicht anhaftete. Daraus erwächst die Scham, «eigne allg e m e in e Gedanken» zu haben.

In späteren Werken lernte Nietzsche mit dem beschriebenen Dilemma immer besser umzugehen. Er interpretierte die Unreife früherer Phasen in seinen Büchern und besprach diese ausgiebig. In der Vorrede zur Genealogie der Moral von 1886 gibt Nietzsche seine geänderten Ansichten samt Kritik, Seitenangaben und biografischem Kontext wieder. Nachdem er berichtet, wie er 1877 über Paul Rées Ursprung der moralischen Empfindungen ein Interesse für moralgenealogische Fragen entwickelt hat, kommt er auf Menschliches und den Wanderer zu sprechen:

Damals brachte ich, wie gesagt, zum ersten Male jene Herkunfts-Hypothesen an's Tageslicht, denen diese Abhandlungen gewidmet sind, mit Ungeschick, wie ich mir selbst am letzten verbergen möchte, noch unfrei, noch ohne eine eigne Sprache für diese eignen Dinge und mit mancherlei Rückfälligkeit und Schwankung. ${ }^{124}$

123 N. an Gast, 5.10.1879, Nr. 889, KGB II 5, S. $45^{2}$.

124 GM, Vorrede 4, S. 251. Und ebd.: «Im Einzelnen vergleiche man, was ich Menschl. Allzumenschl. S. 51 über die doppelte Vorgeschichte von Gut und Böse sage (nämlich aus der Sphäre der Vornehmen und der der Sklaven); insgleichen S. 119 ff. über Werth und Herkunft der asketischen Moral; insgleichen S. 78. 82. II, 35 über die 〈Sittlichkeit der Sitte>, jene viel ältere und ursprünglichere Art Moral, welche toto coelo von der altruisti- 
In der Folge gibt Nietzsche zahlreiche Textstellen an, welche sein «Ungeschick» bezeugen. Die früheren Aphorismenbände erscheinen ihm rückblickend wie Bücher fremder Autoren, in denen unpräzise und unvollständige Gedanken stehen. Nietzsche gibt die Unreife seiner vorherigen Überlegungen offen zu und bekennt sich damit abermals zur Philosophie des Werdens. Er muss nicht länger revidierte Auflagen oder Makulaturen vornehmen, sondern 〈bloss〉 neue Bücher schreiben.

\section{Aktualität vs. Reife}

Das rasche Aufzeichnen und Publizieren widerstrebt nicht nur den Kontinuitätserwartungen, sondern auch der Vorstellung der Gedankenreife. Malwida von Meysenbug ist schon 1876 die neue Zeitlichkeit von Nietzsches Denken negativ aufgefallen. Sie erinnert sich, dass Nietzsche ihr in Sorrent einen Stapel Papiere mit frisch gesammelten Gedanken von Spaziergängen zum Lesen gab: Es seien wunderbare Gedanken darunter gewesen, aber auch solche, die «gar nicht zu Nietzsche, wie er bisher gewesen, paßten». ${ }^{125}$ Konsequent empfahl von Meysenbug, diese Gedanken nicht sofort zu publizieren und sie «ruhen zu lassen, um sie nach längerer Zeit wieder durchzusehen, ehe er sie in den Druck gäbe». ${ }^{126}$ Insbesondere die Gedanken über Frauen hielt von Meysenbug für sehr unausgereift, weil Nietzsche «noch viel zu wenig Frauen wirklich kenne. [...] Leider fand ich jene Sätze nur zu bald veröffentlicht, in einer Schrift 〈Menschliches, Allzumenschliches〉 betitelt».127 Von Meysenbug ärgert sich darüber, dass frische Gedanken ohne längeren Reifeprozess in den Druck gelangen.

Einige Textstellen wirken wie Legitimationen für die zeitgenössischen Vorwürfe der Unreife und Unvollständigkeit. So heisst es in den Vermischten

\section{Meinungen:}

Gegen die Tadler der Kürze. - Etwas Kurz-Gesagtes kann die Frucht und Ernte von vielem Lang-Gedachten sein: aber der Leser, der auf diesem Felde Neuling ist und hier noch gar nicht nachgedacht hat, sieht in allem Kurz-Gesagten etwas Embryonisches, nicht ohne einen tadelnden Wink an den

schen Werthungsweise abliegt (in der Dr. Rée, gleich allen englischen Moralgenealogen, die moralische Werthungsweise an sich sieht); insgleichen S. 74. Wanderer S. 29. Morgenr. S. 99 über die Herkunft der Gerechtigkeit als eines Ausgleichs zwischen ungefähr Gleich-Mächtigen (Gleichgewicht als Voraussetzung aller Verträge, folglich alles Rechts); insgleichen über die Herkunft der Strafe Wand. S. 25. 34., für die der terroristische Zweck weder essentiell, noch ursprünglich ist (wie Dr. Rée meint: [...]).»

125 Von Meysenbug 1905, S. 67.

126 Ebd.

127 Ebd., S. 67f. 
Autor, dass er dergleichen Unausgewachsenes, Ungereiftes ihm zur Mahlzeit mit auf den Tisch setze. ${ }^{128}$

Insbesondere Aphorismen und Sentenzen wurden in der Regel erst im Alter oder postum gedruckt, woraus sich die Lesererwartung der langgereiften Früchte eines weisen Lebens speist. Je verdichteter und allgemeiner die Gedanken daherkommen, desto mehr müssen sie laut Aristoteles durch Lebenserfahrung verbürgt sein: «In Sentenzen zu sprechen aber schickt sich dem Alter nach für die älteren Menschen, und zwar in bezug auf die Dinge, über die man Erfahrung besitzt. Folglich ist für den, der sich noch nicht in einem solchen Alter befindet, das Reden in Sentenzen unschicklich [...].» ${ }^{129}$ Es ist jedoch dieses unschickliche Unternehmen, dem Nietzsche sich in seiner Philosophie des Werdens widmet. Diese Problematik wurde noch bis ins 19. Jahrhundert dadurch verschärft, dass man das Unfertige, Unvollkommene und Vorläufige als unwürdig zur Veröffentlichung ansah. ${ }^{130}$ Sogar Diderot, ebenfalls ein Repräsentant der Aufzeichnung frischer Empfindungen, warnte vor der raschen Publikation:

Die alten Schriftsteller und Kunstrichter unterrichteten sich vor allen Dingen selbst; sie begaben sich nicht eher auf die Bahn der schönen Wissenschaften, als bis sie aus den Schulen der Weltweisheit kamen. Und wie lange behielt der Autor nicht sein Werk bey sich, ehe er es ans Licht treten ließ? So wurde es denn auch reif; und Rath und Zeit und Feile machten es vollkommen. Wir wollen uns gar zu bald zeigen, und haben, wenn wir die Feder ergreiffen, doch weder Einsicht noch Redlichkeit genug. ${ }^{131}$

Das Prinzip der Feile und der Reife schützen bei Diderot vor der fehlenden Einsicht und Redlichkeit beim Zeitpunkt der Niederschrift. Es ist bezeichnend, dass Paul Rée sein für Nietzsche prägendes Sentenzenbuch Psychologische Beobachtungen anonym unter folgender Angabe auf dem Titelblatt veröffentlicht: «Aus dem Nachlass von ${ }^{* * *}{ }^{*}{ }^{132}$ Rée will die Leser dazu verführen, die vorliegenden Sentenzen als wertvolle Einsichten eines weisen, alten Mannes zu lesen. Die Identität des jungen Autors hätte die Autorität des Sentenzenstils untergraben. Nietzsche schreibt im Wanderer, dass es einem Denker am meisten behage, wenn die Leser eine Meinung so wahrnehmen, «als sei sie nicht

\footnotetext{
128 VM 127, KSA 2, S. 432.

129 Aristoteles 1993, Rhet. II, Kap. 21, 9, S. 138. Vgl. auch die eingangs des Kap. 4 zitierte Briefstelle von Nietzsche an Ritschl.

130 Vgl. Grésillon 1999, S. 116.

131 Diderot 176o, Bd. 2, S. 466. Zur raschen Schreibweise vgl. Diderot 1969, S. 715 .

132 Vgl. Rée 1875 .
} 
die unsrige, ja als gienge sie über unsern Horizont hinaus: zum Beispiel wenn der Alte, Alterfahrene einmal ausnahmsweise den Schrein seiner Erkenntnisse aufschliesst.» ${ }^{133}$ Die Philosophie des Werdens ist deshalb das Gegenstück zu Schopenhauers Aphorismen zur Lebensweisheit, welche in der Tradition von Balthasar Gracian's Handorakel dem Leser die Früchte eines langen Nachdenkens und Lebens mitteilen. La Rochefoucaulds Sentenzen, die Nietzsche und Rée als Vorbild dienten, wurden erst nach langem Zögern und dem Einholen vieler Meinungen aus dem Bekanntenkreis veröffentlicht. ${ }^{134}$ Sogar der «sudelnde> Lichtenberg warnt davor, das Geschriebene sogleich drucken zu lassen: «Was mich allein angeht denke ich nur, was meine guten Freunde angeht sage ich ihnen, was nur ein kleines Publikum bekümmern kann schreibe ich, und was die Welt wissen soll wird gedruckt.» ${ }^{135}$ Da beispielsweise Chateaubriand seine Memoires d'outre-tombe zu keinem zufriedenstellenden Abschluss brachte, konnten diese erst nach seinem Tod veröffentlicht werden. Es ist im Unterschied zu Nietzsche bezeichnend, dass Chateaubriand zwar ständig an seinen Memoires arbeitete, diese jedoch nie veröffentlichte. Er vernichtete sogar jene Blätter, welche er zwischenzeitlich verändert hatte, um immer nur eine aktuelle Version zu haben. Almuth Grésillon schreibt dazu: «Es gilt zu verbergen, was die Zeit entwertet hat, und der Nachwelt nur das vollkommene Bild von sich selbst zu hinterlassen.» ${ }^{136}$

\subsubsection{Fazit}

Das rasche Notieren und Publizieren bilden die materiale Grundlage der Philosophie des Werdens. Um das Werden festzuhalten, bedarf es Techniken der raschen Verarbeitung. Erst das Notizbuch und die durch Spaziergänge regulierte Bindung der Notizen an die Lebenszeit ermöglichen die praktische Umsetzung des «unversehens» entstandenen Buches. ${ }^{137}$ Das Widersprüchliche, Unvollständige und Unausgereifte ist in diesem Sinne authentischer und redlicher Ausdruck einer Philosophie des Werdens. Das Werden ist also nicht bloss das Thema von Nietzsches Denken, sondern resultiert aus produktions- und publikationspraktischen Massnahmen. Nietzsche fand mit der St. Moritzer Schreibsituation im Sommer 1879 einen Weg, seine Philosophie an seine persönliche Entwicklung zu koppeln. Der Wanderer ist kein Buch mehr, das Manuskripte aus verschiedenen Orten und Zeiten versammelt und verarbeitet.

\footnotetext{
133 WS 260, KSA 2, S. 665.

134 Hess 1957 , S. 6.

135 Lichtenberg 1968, Bd. 1, B 272, S. 117. Man kann sich darüber streiten, ob die Sudelbücher wirklich nicht für den Druck bestimmt waren.

136 Vgl. Grésillon 1999, S. 116.

137 WS 121, KSA 2, S. 604.
} 
Hier verbinden sich Philosophie und Schreibsituation in der konsequenten Umsetzung der Philosophie des Werdens. Nietzsche ist fortan auf dem Weg zu jener Autorschaft, die ihn als Philosoph des Werdens, als perspektivenreichen, widersprüchlichen und gewitzten Philosophen ausmachen wird. Der in der Fröhlichen Wissenschaft als «Kunst der Transfiguration» bezeichnete Gang durch viele Gesundheiten bzw. Philosophien ist als Philosophie in der Entwicklung von Nietzsches Schreibsituationen bereits angelegt: «diese Kunst der Transfiguration is t eben Philosophie.» ${ }^{138}$

Mit dem Wanderer als Abschluss einer ersten Serie von Aphorismenbüchern ist die durch Schreibverfahren und Publizierweise ausgeübte Philosophie des Werdens performativ umgesetzt. Die Summe der Aphorismenbücher gibt dann nebeneinandergestellt dem Leser ein Bild des philosophischen Werdegangs des Autors. Nietzsche erzeugt durch seine «Philosophie des Werdens» eine Aufmerksamkeitsökonomie, die immer über das eigene Werk und die an ihm vorgebrachte Kritik hinausgeht. Der Wanderer als Verdichtung von Nietzsches Denken im Sommer 1879 kann durch weitere Gedankensammlungen auf vielfache Weise rekursiv umgedeutet, umgewertet und weiterentwickelt werden. Schon nach wenigen Publikationen entsteht ein dicht verzweigtes Geflecht, in dem sich die Leser auf unzählige Arten bewegen können. Es ist darum nicht verwunderlich, dass Nietzsche als sein eigener Leser in Ecce Homo einen möglichen Werdegang ausgeführt und kommentiert hat.

Angesichts der hier dargelegten Philosophie des Werdens können einige Interpretationen der Nietzscheforschung kritisiert werden. Zunächst ist dem von Nietzsche selbst stilisierten Klischee zu entgegnen, es habe ihm für umfassende Abhandlungen die gesundheitliche Ausdauer gefehlt. Nietzsche hat durch diesen Konnex von Kurztexten und Krankheit eine lange einseitige Interpretation seiner Aphorismenbücher als Mängelprodukte eingeleitet. Seit den Anfängen der Nietzscheforschung wurde die gesundheitliche Verfassung Nietzsches als Hauptgrund für den Aphorismenstil gesehen. ${ }^{139}$ So ist Fritz Koegel, damaliger Herausgeber am Nietzsche-Archiv, überzeugt, dass bei mehr Zeit und Konzentration aus Menschliches eine weitere zusammenhängende Schrift in der Reihe der Unzeitgemässen Betrachtungen entstanden wäre. ${ }^{140}$

\footnotetext{
138 FW, Vorrede 3, KSA 3, S. 349.

139 Janz sieht diese Umstände als konstitutiv für den Aphorismenstil. Nietzsche habe nur «widerwillig» in Aphorismen geschrieben (1978, S. 32). Vgl. auch Stingelin 2002, S. 97 f. und Kittler 2003, S. 230.

140 Vgl. Koegel im Vorwort der GAK, Bd. 9, S. XIX. Nietzsche hat gemäss Koegel aus der «Noth eine Tugend» gemacht (S. XX). Vgl. auch Kaftan über die mittleren 1870er Jahre: «Es war ihm damals nicht möglich, anhaltend geistig zu arbeiten; er musste die Stunden benutzen, die ihm geschenkt wurden.» (Kaftan 1906, S. 10).
} 
Diese Haltung wurde mitunter durch die von Koegel herausgegebene Werkausgabe nahegelegt. Die hier vorgetragenen Befunde der raschen Aufzeichnung und Publikation der mittleren Aphorismenbücher wird von Koegel zwar erkannt, jedoch als Folge des gesundheitlichen Zustands dargestellt. ${ }^{141}$ Sicher waren die voneinander unabhängigen, kurzen Aphorismen einer geringen Schreib-, Lese- und Seh-Ausdauer angepasst. Der Zusammenhang der Philosophie des Werdens mit der Aphorismenproduktion geht jedoch weit über das Format des Kurztextes hinaus. So gilt für Nietzsche nach den hier vorgebrachten Argumenten gerade nicht, was Edmund Heller für die Zeit nach 1875 festgestellt hat:

Nietzsche hat in der Zeit um 1875 entschieden, Ergebnisse eines nicht zu einem vorläufigen Ende gebrachten Forschens von vornherein öffentlich mitzuteilen, weil er der Ansicht war, mit Problemen befaßt zu sein, die so komplex und schwierig sind, daß er selbst zu einer in konventioneller Form noch mitteilbaren Lösung nicht kommen konnte. ${ }^{142}$

Diese Sicht widerspricht der Produktionsweise sowie der Werkpolitik der Philosophie des Werdens. Nietzsche hat absichtlich zeitnah publiziert, wobei der offene Denkprozess ohne «letztes Ziel» zum philosophischen Programm gehört. Es gab 1879 kein überkomplexes Projekt, das Nietzsche nur in «vorläufiger» Form behandeln konnte. Heller nährt den Mythos des primordialen Denkens, dessen postume Verschriftlichung immer nur unzureichend zur Darstellung gelangt. Der enge Zusammenhang des «wirre[n] Haufe[ns]» der Notizbücher und den lose geordneten mittleren Aphorismenbücher bezeichnet eine Werkpolitik, die Teil der Philosophie des Werdens ist. ${ }^{143}$

Des Weiteren werden der Perspektivismus und die Redlichkeit in der Nietzscheforschung oft als Mentalitätszustände behandelt. ${ }^{144}$ Nietzsches Perspektivismus muss aber zusammen mit der materialen Produktions- und Publikationsweise gedacht werden. Zwischen dem Wechsel der Perspektiven und Philosophien stehen Manuskripte, Bücher und Praktiken: Lektürepraktiken, Schreibpraktiken, Denkpraktiken, Esspraktiken etc. Zumindest für den mittleren Nietzsche ist eine materiale, körperliche und zeitliche Dimension des Werdens festzustellen, welche nur im Fortlauf des persönlichen Lebens registriert werden kann. Es handelt sich um ein Nacheinander von Perspektiven und Philosophien - nicht um ein gleichzeitiges Miteinander. Erst mit steigender

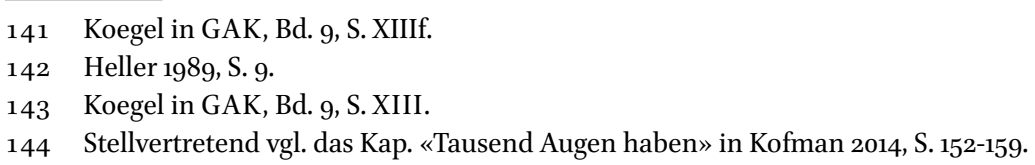


Publikationszahl und Werkausgaben entsteht aus der Synopse publizierter Ansichten ein Perspektivismus. Nietzsche steigert sich wie am Beispiel des Krieges oder der Diätetik ersichtlich in einzelne Perspektiven hinein, um sie dann wieder zu verlassen. Ohne das Selbstexperiment des Hineinsteigerns (das Feuer der Leidenschaft), wäre der Perspektivismus ein blosses Gedankenspiel. Das Charakteristische an Nietzsches werdendem Perspektivismus ist nicht die Gleichzeitigkeit, sondern das durch Schreibsituationen beschleunigte Nacheinander: «Nietzsche évolue, Nietzsche change, comme tout philosophe. Mais il va plus vite que Platon, Descartes ou Kant, et cette rapidité peut donner l'impression, aux interprètes un peu lents, qu'il se contredit.» ${ }^{145}$ Aus diesem Grund funktioniert auch die Beachtung von Werkphasen in Nietzsches Schaffen vergleichsweise gut als Erklärungsmethode.

Auch die von Nietzsche ab 1880 häufig geforderte «Redlichkeit gegen sich» ist nicht bloss eine psychologische Einsicht in seine Beziehung zu Wagner und der damit einhergehenden Lebenskrise. ${ }^{146}$ Vielmehr beruht diese Einsicht auf der Echtzeitphilosophie und drei Aphorismenpublikationen in eineinhalb Jahren. Die Redlichkeit ist deshalb auch eine philosophische Produktionsund Publizierweise, die sich über die Echtzeitphilosophie performativ realisiert. Einmal mehr handelt es sich bei zentralen philosophischen Forderungen Nietzsches nicht um rein intellektuelle Konstrukte, sondern um Verfahrensweisen. Das Letztere in der philosophischen Rezeption schwierig wahrnehmbar sind, hängt auch mit der Routine zusammen, eine Gesamtwerkausgabe als mehr oder minder kohärentes Resultat einer Philosophie zu lesen. Dieses Vorgehen ist zum Nachvollzug einer Philosophie des Werdens - d.h. einer Philosophie, die sich performativ in der Abfolge von Schreibsituationen und Publikationen entfaltet - denkbar ungünstig.

Da der Wanderer die Durchlässigkeit von Schreibsituation und Buchform zum Thema hat, betreibt Nietzsche in dreifacher Hinsicht eine Buchphilosophie. Erstens schrieb er durch gezielte Schreibverfahren ein philosophisches Buch. Zweitens bezog er die Materialität des Buches und die Produktionsprozesse stets in seine Philosophie mit ein. Drittens antizipierte er auf vielfache Weise den zeitgenössischen und zukünftigen Buchmarkt für philosophische Bücher - Nietzsche besass eine Werkpolitik.

145 D'Iorio/Ponton 2004, S. 4. Vgl. auch Nietzsches Aufforderung von 1881: «Aber aus Einem in einen Anderen übergehen und eine Reihe von Wesen durchleben!» (NL 1881, $11[304]$, KSA 9, S. 558).

146 Brusotti 1994, S. 451. 


\subsection{Schreibsituation und Experimentalsystem}

Die St. Moritzer Schreibsituation und ihre vom Autor auferlegten Bedingungen weisen einen Experimentcharakter auf. Die spezielle Anordnung und Inszenierung der Schreibsituation kann als Prototyp des ab der Morgenröte stark thematisierten «Experiments» und «Versuchs» verstanden werden. ${ }^{147}$ Aus diesem Grunde geht die Diätetik des Lesens und Schreibens weit über eine metaphorische Veranschaulichung hinaus. Der Philosoph kann gleich einem Chemiker in der Laborsituation seine Lebensumstände gezielt verändern, um eine 〈andere〉 Philosophie zu erzeugen. Die Wahl der Diät, des Orts oder des Klimas werden zu philosophischen Entscheidungen. Das Reisen wird beispielsweise zur Selbsttechnik des Denkens: Will man eine «südliche〉 Philosophie, begibt man sich in die südliche Schweiz oder nach Italien. Zudem kann durch verschiedene Diätvarianten oder Wohnsituationen der eigene Körper und damit wiederum das Denken beeinflusst werden. ${ }^{148}$ Hier ist bereits die Philosophie als Experiment sowie das Leben als philosophisches Experiment angelegt.

Dieser äussere Experimentcharakter zeigt sich auch innerhalb der entstehenden Notizbücher, weil letztere selber Experimenträume des Denkens sind. Notizbücher sind Tools für eine philosophische Empirie, die von der Selbsterfahrung ausgeht. Eine solche Auffassung des Schreibens verbreitete sich im 19. Jahrhundert zunehmend und wurde bereits von Lichtenberg eindrücklich beschrieben: «Zu Aufweckung des in jedem Menschen schlafenden Systems ist das Schreiben vortrefflich, und jeder der je geschrieben hat, wird gefunden haben, daß Schreiben immer etwas erweckt was man vorher nicht deutlich erkannte, ob es gleich in uns lag.» ${ }^{149}$ Die Vorstellung, durch eine Technik ein verborgenes System aufzuwecken, ist die Grundidee jedes Experiments. Dies bedingt bereits einen experimentellen Begriff vom Schreiben als einer Tätigkeit, welche Gedanken hervorbringt, die man erstens noch nicht kennt und die zweitens ohne den Akt des Schreibens nicht entstehen würden. Mit der handwerklichen Auffassung von Schreiben und dem Experimentcharakter der St. Moritzer Schreibsituation nimmt Nietzsche einiges von Ernst Machs Ansichten der 189oer Jahre vorweg. Wie zuvor Nietzsche bestimmt auch Mach «die Differenzen und Gemeinsamkeiten zwischen künstlerischen, wissenschaftlichen und anderen Entwurfsprozessen allein pragmatisch und

147 Vgl. Zimmer 2010. Brusotti bemerkt zwar die Bedeutung des Wanderers bezüglich der produktiven Gestaltung des eigenen Lebens, bleibt aber relativ abstrakt in seiner Begründung (1997, S. 466).

148 Vgl. für das Gebot des konstanten Wechsels von Diät, Klima, Ort etc. NL 1881, 11[258], KSA 9, S. 539 (weiter unten vollständig zitiert).

149 Lichtenberg 1968, Bd. 2, J 19, S. 653. 
nicht über metaphysische oder anthropologische Kategorien.» ${ }^{150}$ Des Weiteren begreift Mach das «Gedankenexperiment» als empirische Denkerfahrung, die wie alle empirische Forschung durch geeignete Experimentsituationen angeregt werden kann. Nietzsche erzeugt in St. Moritz gewissermassen durch ein strategisches Programm sein empirisches Denkmaterial.

Mit dem Experimentcharakter der Schreibsituation erhellt sich eine weitere Bedeutung der Wandererfigur. Wie am Ende von Menschliches beschrieben, hat der Wanderer kein festes Ziel. Dem entspricht der Philosoph, welcher keine systematischen Erkenntnisse, sondern neue Gedanken sammelt. Nietzsche führt im Herbst 1878 die Haltung des Wanderers auf das Merkmal der unerwarteten Begegnungen zurück: «Emerson meint, «der Werth des Lebens läge in den unergründlichen Fähigkeiten desselben: in der Thatsache, daß ich niemals weiß, wenn ich mich zu einem neuen Individuum wende, was mir widerfahren mag.> Das ist die Stimmung des Wanderers.» ${ }^{151}$ In St. Moritz geht es aber weniger um die Begegnung mit anderen Individuen, als um jene mit neuen Gedanken, Erkenntnissen und Notaten. Es geht darum, sich selbst beim Wandern auf unerwartete Weise zu begegnen. Ebendies ist die titelgebende Begegnung zwischen Wanderer-Autor und Schreibsituation.

Was lässt sich abschliessend auf Rheinbergers einleitend zitierte Vermutung erwidern, «ob nicht das Schreiben für den Geisteswissenschaftler so etwas wie ein Experimentalsystem darstellt»? ${ }^{152}$ Rheinberger argumentierte in seinen Studien, dass «Experimentalsysteme» für die Naturwissenschaften die treibenden Kräfte der Wissensproduktion sind. Unter der Prämisse, neues Wissen zu produzieren, schaffen Experimentalsysteme Spielräume, in denen Wissenschaftler Resultate hervorbringen. Dabei geht Rheinberger von einem «Wechselspiel» zwischen so genannten epistemischen und technischen Dingen aus. Die technischen Dinge «verleihen dem Experimentalsystem in Form von Forschungstechnologien - Apparaturen, Messvorrichtungen, Workflows usw. - Gestalt, Kontur und ein gewisses Maß an Stabilität.» ${ }^{153}$ Technische Dinge bezeichnen also die ganze Bandbreite einer experimentellen Infrastruktur,

150 Krauthausen 2010, S. 9. Dies zeigt sich exemplarisch an der verblüffenden Ähnlichkeit von MA 162 (KSA 2, S. 151f.; Kap. 3.1.1 und 4.1) und Ernst Machs folgender Aussage: «Der Projektenmacher, der Erbauer von Luftschlössern, der Dichter socialer oder technischer Utopien experimentiert in Gedanken. Aber auch der solide Kaufmann, der ernste Erfinder oder Forscher thut dasselbe. Alle stellen sich Umstände vor, und knüpfen an diese die Vorstellung, Erwartung, Vermutung gewisser Folgen, sie machen eine Gedankenerfahrung.» (Mach 1897, S. 1).

151 NL $1878,32[15]$, KSA 8, S. 562.

$15^{2}$ Rheinberger 2011, S. 279. Vgl. zum Experimentalsystem generell Rheinberger 1992, S. 24-32.

153 Rheinberger 2014, S. 194. 
von der materiellen Technik bis hin zu Begriffen und Denkweisen: «Die technischen Dinge schreiben Randbedingungen der Experimentalsysteme fest und erzeugen damit einen Spielraum, innerhalb dessen sich ein epistemisches Objekt entfalten kann.» ${ }^{154}$ Epistemische Dinge hingegen sind «unscharf»: «Sie verkörpern gewissermaßen das, was man noch nicht weiß.»155 Um die Dynamik von technischen und epistemischen Dingen zu entfalten, bedarf es eines Experimentalsystems, d.h. einer situativen Begrenzung dieses Geschehens: «Experimentalsysteme werden so als bewegliche, zeitlich limitierte Gebilde begriffen, in denen sich die Schaffung neuen Wissens abspielt und aus denen heraus der gegebene Wissensstand beständig überschritten wird.» ${ }^{156}$ Auch das Schreiben könne als Experimentalsystem verstanden werden: «Das Schreiben hat etwas mit Fixieren zu tun, aber eben auch mit offen lassen, wie das auch für Experimente und für Experimentalsysteme gilt [...].»157 Dieser Aspekt von Experimentalsystemen ist auch konstitutiv für Nietzsches Schreibverfahren und Buchherstellung.

Die St. Moritzer Schreibsituation ist ein «Glücksfall〉, weil sie sich durch die Kohärenz des Materials und des Zeitraums gleichsam als Experimentalsystem präsentiert. Die Landschaft, die Spaziergänge, die Diät, das Notizbuch und der Bleistift gehören bei Nietzsche zunehmend zur Infrastruktur, innerhalb der die epistemischen Dinge bzw. philosophischen Gedanken sich ereignen. Das Notizbuch beispielsweise bietet als technisches Ding eine Denkumgebung an, in der sich epistemische Dinge - Fragwürdigkeiten - ergeben können. Diese Offenheit und Unschärfe ist es, welche das Notizbuch als Teil einer Schreibsituation produktiv macht, weil stets ein unscharfer Anteil philosophischen Überschusses in der offenen Form des Notats vorhanden ist. Das eher technische Ding des Notizbuchs und die in der Materialität der Notate aufgehobenen Philosopheme können nicht voneinander getrennt werden. Es ist diese Kontinuität der experimentell angelegten Schreibsituation, die Nietzsche in der Beschreibung seines Schreibverfahrens hervorhob: «Alles ist, wenige Zeilen ausgenommen, unterwegs erdacht und in 6 kleine Hefte mit Bleistift skizziert worden: das U m schreiben bekam mir fast jedesmal übel.» ${ }^{158}$ Nietzsche sieht den Wanderer als Transformation von Inskriptionen und Schreibprozessen, die ihren Ausgang auf St. Moritzer Spaziergängen nahmen. Er betont demnach nicht nur die rekursiv aufeinander bezogenen Schreibprozesse, sondern

154 Rheinberger 2006, S. 314

155 Rheinberger 2014, S. 194.

156 Ebd., S. 193.

157 Rheinberger 2011, S. 280.

158 N. an Gast, 5.10.1879, Nr. 889, KGB II 5, S. $45^{\circ}$. 
auch die St. Moritzer Schreibsituation. Die Praktiken des Reisens, der Diät, des Spazierens ermöglichen eine räumliche und zeitliche Begrenztheit, ohne die sich das Experimentalsystem in der diffusen Unordnung des Autorlebens verlieren würde.

Die zentrale Eigenschaft eines Experimentalsystems ist deshalb dessen Reproduktion, während das neue Wissen gleichsam als Nebenprodukt dieses Prozesses entsteht: «Die zeitliche Kohärenz verdankt ein Experimentalsystem seiner Reproduktion, und seine Entwicklung hängt davon ab, ob es gelingt, in ihm Differenzen zu erzeugen, ohne seine reproduktive Kohärenz zu zerstören.» ${ }^{159}$ Auf den Wanderer übertragen heisst dies, dass die St. Moritzer Schreibsituation im Optimalfall an anderen Orten ebenfalls durchführbar ist und dabei andere Gedanken (sprich Differenzen) entstehen lässt. Die reproduktive Kohärenz wird durch die Bestandteile der Schreibsituation und der Schreibverfahren garantiert. ${ }^{160}$ Die Durchführung von Schreibsituationen ist für Nietzsches Philosophie des Werdens zentraler als die dabei entstehenden Meinungen. Die Lebensweise wird zum produktiven Motor der Philosophie: «Der Diätetik geht es nicht um Gesunderhaltung, sondern um das Gesunden, d. h. um das Werden.» ${ }^{161}$ Indem Nietzsche sein Denken in einer Experimentalsituation erzeugt, kann er dessen produktive Differenzerzeugung in Form verschiedener Notate nutzen. Einer solchen Philosophie geht es um stetige Veränderung des eigenen Denkens, das sich in zyklisch gesammelten Notaten manifestiert.

Nietzsche hat 1877 seine optimalen Arbeitsbedingungen aufgezählt und damit im übertragenen Sinne sein Experimentalsystem beschrieben:

Hätte ich doch irgendwo ein Häuschen; da gienge ich wie hier täglich 6-8 Stunden spazieren und dächte mir dabei aus, was ich nachher im Fluge und vollkommener Sicherheit auf's Papier hinwerfe - so habe ich's in Sorrent, so hier gemacht und einem im Ganzen unangenehmen und verdüsterten Jahre viel abgewonnen. ${ }^{162}$

159 Rheinberger 1992, S. 26. Vgl. zum Zusammenhang von Experimenten, Reproduktion und Differenzerzeugung auch das Abschnitt «Beobachtung, Experiment, Erfahrung» in Fleck 1980, S. 111-129, bes. 114f.

16o In anderen Worten kommt hier eine Eigenschaft von Experimentalsystem zum Vorschein, die Nietzsche in Menschliches als zentrale Errungenschaft der Wissenschaft bestimmte: die Methoden, vgl. Kap. 3.3.1.

161 Benne 2015b, S. 37. Gemäss Benne sei Nietzsche nicht am Resultat der Verdauung interessiert: «Ihn [Nietzsche] fasziniert vielmehr der nie abreißende Prozess der Einverleibung selbst. Die Dyspepsie ist lediglich negatives Pendant des an sich uninteressanten Resultats.» (ebd.).

162 N. an Overbeck, 28.8.1877, Nr. 654, KGB II 5, S. 276. 
Nietzsche lernte in der Schreibsituation von St. Moritz, dass das für ihn optimale Experimentalsystem unter modifizierten Bedingungen wiederholbar ist. Sils Maria wird bekanntlich zum zukünftigen Durchführungsort der «Gedanken-Gänge». Fortan ging es darum, in periodischen Abständen und Verfeinerungen dieses Setting weiterzuentwickeln. In einem bezeichnenden Notat von 1881 findet sich eine Liste von sechs Anweisungen über die «Kur des Einzelnen»:

1) er soll vom Nächsten und Kleinsten ausgehen und die ganze Abhängigkeit sich feststellen, in die hinein er geboren und erzogen ist

2) ebenso soll er den gewohnten Rhythmus seines Denkens und Fühlens, seine intellektuellen Bedürfnisse der Ernährung begreifen

3) Dann soll er Veränderung aller Art versuchen, zunächst um die Gewohnheiten zu brechen (vielen Diätwechsel, mit feinster Beobachtung [sic]

4) er soll sich geistig an seine Widersacher einmal anlehnen, er soll ihre Nahrung zu essen versuchen. Er soll re is e n, in jedem Sinne. In dieser Zeit wird er «unstät und flüchtig» sein. Von Zeit zu Zeit soll er über seinen Erlebnissen ruhen - und verdauen.

5) Dann kommt das Höhere: der Versuch, ein Ideal zu dichten. Dies geht dem noch Höheren voraus - eben dies Ideal zu leben.

6. $\quad\left[\right.$ sic] Er muß durch eine Reihe von Idealen hindurch. ${ }^{163}$

Der konstante Wechsel von Diät, Klima, Ort, Lektüre etc. ist die materiale Grundlage der Philosophie des Werdens. Das «Brechen» der Gewohnheiten sowie die Beobachtung neuer Meinungen bedürfen einer Infrastruktur, welche die Schreibsituation und die Lebensform leisten müssen. Die Aphorismenbücher sind die Nebenprodukte dieses Experimentierens mit der Schreibsituation. Nietzsches optimale Schreibsituation wurde in den späten $1870 e r$ Jahren zum Werkzeug seiner weiteren Produktion, indem er fortan die Kurorte und die Notizbücher für seine spazierende Denktätigkeit nutzte. Die Philosophie des Werdens fordert als Konsequenz von Nietzsches Schreibverfahren auf philosophischer Ebene, was in einem Experimentalsystem angelegt ist: das ständige Vorwärtstreiben des Experimentalsystems und damit verbunden die Überbietung des Gegebenen. Die Schreibsituation wird während den ersten drei Aphorismenbüchern zu einem Experimentalsystem, das sich von den Resultaten bzw. Aphorismen emanzipiert. ${ }^{164}$ Wenn sich die Philosophie des Werdens gegen Resultate, Vollkommenheit und System auflehnt, dann hat sich der philosophische Fokus vom Resultat zum Experimentalsystem verlagert.

163 NL 1881, 11[258], KSA 9, S. 539. Vgl. dazu die Liste in Nietzsches Emerson-Ausgabe (Kap. 3.3.6; Abb. 25).

164 Vgl. Rheinberger 2014, S. 194. 
Und wenn Nietzsche betont, dass er bei jeder Publikation bereits ein anderer sei, dann heisst dies auch, dass ihn die weiteren Durchführungen seiner Schreibsituation mehr interessieren als die vergangenen Resultate. Die abgeschlossene Drucklegung begrenzt die Schreibsituation und drängt gleichzeitig auf eine neue Durchführung. Deshalb sind für Nietzsche Ortswechsel als Variationen seiner Schreibsituation wichtig: Ob Sorrentiner Manuskripte (Winter 1876/77), «St. Moritzer Gedanken-Gänge» (1879), «L'Ombra di Venezia» (1880), die Genueser Morgenröte (1881), Idyllen aus Messina (1882) oder das späte Lenzerheide-Fragment (1887); stets ist die Schreibsituation Teil seiner Philosophie. Nietzsches Perspektivismus - die sich anhäufenden Aphorismen und Bücher ergibt sich aus der Wiederholung des St. Moritzer Experiments.

Aufgrund der Fallstudie der Wanderer-Manuskripte kann erwogen werden, ob die «Schreibsituation» für Nietzsche eine ähnliche Antriebsfunktion übernahm, wie Rheinberger das mit dem «Experimentalsystem» für die Laborwissenschaften beschrieb. Die Schreibsituation umfasst nicht nur die Materialität des Schreibens (Schreibzeug, Schreibmaterialien etc.), sondern auch kulturelle Praktiken wie Diäten und individuelle Haltungen zum eigenen Schreiben und zur Autorschaft. Erst dieser erweiterte Hybrid enthält auf die Philosophie übertragen alle Bedingungen, «die nötig sind, um einen integralen Forschungsprozeß zu ermöglichen.» ${ }^{165}$ Die Strapazierung des Forschungsbegriffs, welche die Schreibsituation vom Wanderer verlangt, lässt erste Unterschiede einer naturwissenschaftlichen Laborforschung und dem Schreiben eines philosophischen Buches vermuten. Der lebendige Alltag und die schier unbegrenzten Anlässe das Denken in Bewegung zu setzen, sträuben sich gegen die zugerichtete und isolierte Laborsituation. Es deutet sich bereits an, dass der experimentale Charakter der Schreibsituation auf die Lebensform ausgeweitet werden kann. Das Erlebnis, der Einzelne, das Leben als Experiment sind eine Ausweitung der Schreibsituation auf das Leben. ${ }^{166}$ Das zeigt der Werkplan zu «D i e Wie de r-

165 Rheinberger/Hagner 1993, S. 9. Der Fokus auf Schreibprozesse ist zwar ertragreich, aber kann gerade nicht wie Thüring das behauptet, die Entstehung von Nietzsches Aphorismenbüchern erklären, vgl. Thüring 2008, S. 134: «Es schien seine Zeit zu brauchen, bis Nietzsche sich ganz vom systematischen Exzerpieren und Kompilieren zu jenem wilden Kompilieren und Formulieren durchgerungen hatte, bei dem die Grenzen von Lesen und Schreiben, Zitieren oder Paraphrasieren und Umformulieren, Einfälle notieren, Ab-, Umund Neuschreiben im Übergang von verschiedenen, situativ oder textgenetisch bestimmten Heften fließender werden. Erst auf diese Weise konnten die folgenden Bücher des freien Geistes von Menschliches Allzumenschliches bis zur Fröhlichen Wissenschaft in ihrer nietzschetypischen Form oder Unform mit ihren erkenntniskritischen und lebensphilosophischen Themenvariationen entstehen.»

166 Vgl. die kurz nach St. Moritz beginnenden einschlägigen Notate und Aphorismen NL 188o, 6[323], KSA 9, S. 280; NL 1881, 15[59], KSA 9, S. 654f.; FW 110, KSA 3, S. 471. Nietzsche nennt 
kunft des Gleichen», in dem eine Kapitelüberschrift den «Einzelne[n] als Experiment» nennt. Unter diesem Werkplan stehen bezeichnenderweise die viel zitierten Angaben zur Schreibsituation: «Anfang August 1881 in Sils-Maria, 6ooo Fuss über dem Meere und viel höher über allen menschlichen Dingen! $-\gg .{ }^{167}$ Der Werkplan, die Schreibsituation und das Selbstexperiment vermischen sich hier zur Philosophie.

Es wäre noch genauer zu bestimmen, was die «epistemischen Dinge» der Philosophie sind und ob die Darstellungsformen philosophischer Produkte ähnlichen Formierungen folgen wie die naturwissenschaftlichen Experimentspuren. Zudem ist kaum bestimmbar, welche Philosopheme gleichsam als «technische Dinge» die zukünftige Philosophie formieren. Denn es gilt für die Philosophie nachdrücklich, was Ludwik Fleck über Laborexperimente feststellte: «Das Erkennen verändert den Erkennenden [...].» ${ }^{168}$ So wirkt sich die Haltung zur eigenen Autorschaft ebenso auf die entstehende Philosophie wie auf die Wahl zukünftiger Schreibverfahren aus. Nietzsches Kritik an der Genieästhetik sowie seine Hinwendung zur Autorschaft als Handwerk blieben nicht ohne Folgen für die Einrichtung seiner Schreibsituation und die Entwicklung seiner Philosophie. Sie konditionierten als technische Dinge die zukünftigen Philosopheme und Arbeitsweisen. In St. Moritz erarbeitete Nietzsche in einem strategisch handwerklichen Vorgehen sein Material, während die Zeitlichkeit des Handwerks beispielsweise in die Reflexionen zur Demokratie einfloss. Im fluiden Prozess des Denkens bleiben gewisse Philosopheme besonders stabil und werden zu unhinterfragten Dispositionen des weiteren Denkens. Dies gilt auch für die Philosophie des Werdens, welche im Moment ihrer St. Moritzer Anwendung gleichsam als Infrastruktur für weitere Meinungswechsel zu fungieren beginnt und damit langfristig einen Perspektivismus hervorbringt.

Nietzsche exponierte im Wanderer die Schreibsituation im Titel und an zahlreichen Stellen im Buch. In der später hinzugefügten Vorrede bezieht er sich

den Gedanken, «dass das Leben ein Experiment des Erkennenden sein dürfe», in der Fröhlichen Wissenschaft seinen «grosse[n] Befreier» (FW 324, KSA 3, S. 552). Insbesondere die zahlreichen Notate von 188o, in denen Nietzsche über die Möglichkeit eines «Musters» nachdenkt, nach welchem man leben könne, zeugen vom diätetischen Experiment, welches in St. Moritz zur Anwendung kam, vgl. beispielsweise NL 1880, 6[293], KSA 9, S. 273: «Das Ziel ist aber: daß jeder sein Musterbild entwerfe und es verwirkliche das individuelle Muster.»

167 NL 1881,11[141], KSA 9, S. 494.

168 Fleck 1980, S. 114. 
wiederum auf seine biografische Schreibsituation. Das wirft für die Rezeption die Frage auf, inwiefern Nietzsche einen ausschliesslichen Bezug auf sein publiziertes Werk unterwanderte. Beim gelehrten Philologen findet sich bereits in den Unterlagen zu Ritschl's Lehrveranstaltungen folgender Lehrsatz: «Um das Werden zu finden, sind die Vorstufen wichtiger als der Abschluss.» ${ }^{169}$ Der Wanderer und seine Werkpolitik verstossen gegen die Hermeneutik des $<$ reinen Textes> und provozieren den Einbezug der Schreibsituation. Nietzsches Philosophie hält sich in keiner Weise an autorisierte Werke: Er selbst hat den Rückbezug auf die Schreibsituation zur philosophischen Methode erhoben. In Menschliches, in den Vermischten Meinungen und im Wanderer werden Künstler, Schriftsteller und Philosophen massgeblich durch ihre Arbeitsweise charakterisiert. Zudem hat Nietzsche seine Bücher oft von der Schreibsituation her kommentiert. Neben der 1886 nachgereichten Vorrede ist dies im Falle des Wanderers exemplarisch in Ecce Homo geschehen:

Damals - es war 1879 - legte ich meine Basler Professur nieder, lebte den Sommer über wie ein Schatten in St. Moritz und den nächsten Winter, den sonnenärmsten meines Lebens, als Schatten in Naumburg. Dies war mein Minimum: «Der Wanderer und sein Schatten» entstand währenddem. Unzweifelhaft, ich verstand mich damals auf Schatten... Im Winter darauf, meinem ersten Genueser Winter, brachte jene Versüssung und Vergeistigung, die mit einer extremen Armuth an Blut und Muskel beinahe bedingt ist, die «Morgenröthe» hervor. ${ }^{170}$

Im Wanderer nahm die konzeptuelle Verflechtung von Schreibsituation und entstehenden Büchern ihren Ausgang. Sie wurde letztlich zu einem Charakteristikum von Nietzsches Werken und verleiht ihnen bis heute einen unverwechselbaren persönlichen Stil. Mazzino Montinari sah in der Philosophie des Werdens einen der modernsten und faszinierendsten Aspekte von Nietzsches Philosophie: «l'assoluta fluidità del suo pensiero, per quel suo non fermarsi mai a dei risultati, non concludere [...].»171 Das Fluide und Werdende im Denken Nietzsches entsteht durch spezifische Schreib- und Publikationsverfahren, die er als integralen Bestandteil der Philosophie aufzufassen beginnt. Zwar bleiben wie in Rheinbergers wissenschaftshistorischen Untersuchungen die «Materialitäten der Experimentalsysteme» zu Gunsten der losgelösten «begrifflichen Gebäude» im Labor bzw. in der Schreibsituation zurück;

169 GSA 71/43: Blatt 3, zit. n. Benne 2005, S. 335. Die in der Manuskriptkultur zunehmend auftauchenden Notizbücher, Arbeitshefte und Korrespondenzen schaffen durch ihre schiere Existenz eine Spannung zwischen dem «Denklabor` des Philosophen und der entstehenden Philosophie, vgl. dazu Benne 2015a, S. 409 und Rheinberger 2006, S. 351f.

170 EH, KSA 6, S. $264 f$.

171 Montinari an Giorgio Colli, 7.1.1968, zit. n. Campioni 2007, S. 25 f. 
in den philosophischen Begriffsgebäuden kann der Autor aber die Materialität seines Schaffens mobilisieren, indem er sie thematisiert. Der Arbeitstitel «St. Moritzer Gedanken-Gänge» sowie der finale Titel Der Wanderer und sein Schatten spielen mit der eigenen Herkunft aus Manuskripten und Schreibsituationen. Im Wanderer geht es um ein komplexes Verweisspiel zwischen Autor, Schreibsituation und Leser. Der Wanderer ist ein Buch über die Materialität der Philosophie. 